\title{
Detailed Molecular Mechanisms Involved in Drug-Induced Non-Alcoholic Fatty Liver Disease and Non-Alcoholic Steatohepatitis: An Update
}

\author{
Laura Giuseppina Di Pasqua *(D), Marta Cagna, Clarissa Berardo $(\mathbb{D}$, Mariapia Vairetti *(D) and Andrea Ferrigno $\mathbb{D}$
}

check for

updates

Citation: Di Pasqua, L.G.; Cagna, M.; Berardo, C.; Vairetti, M.; Ferrigno, A. Detailed Molecular Mechanisms Involved in Drug-Induced Non-Alcoholic Fatty Liver Disease and Non-Alcoholic Steatohepatitis: An Update. Biomedicines 2022, 10, 194. https://doi.org/10.3390/

biomedicines10010194

Academic Editor: Sanda Win

Received: 19 November 2021

Accepted: 12 January 2022

Published: 17 January 2022

Publisher's Note: MDPI stays neutral with regard to jurisdictional claims in published maps and institutional affiliations.

Copyright: (C) 2022 by the authors. Licensee MDPI, Basel, Switzerland. This article is an open access article distributed under the terms and conditions of the Creative Commons Attribution (CC BY) license (https:/ / creativecommons.org/licenses/by/ $4.0 /)$.

\author{
Unit of Cellular and Molecular Pharmacology and Toxicology, Department of Internal Medicine and Therapeutics, \\ University of Pavia, 27100 Pavia, Italy; marta.cagna02@universitadipavia.it (M.C.); \\ clarissa.berardo01@universitadipavia.it (C.B.); andrea.ferrigno@unipv.it (A.F.) \\ * Correspondence: lauragiuseppin.dipasqua01@universitadipavia.it (L.G.D.P.); mariapia.vairetti@unipv.it (M.V.); \\ Tel.: +39-03-8298-6873 (L.G.D.P.); +39-03-8298-6398 (M.V.)
}

\begin{abstract}
Non-alcoholic fatty liver disease (NAFLD) and non-alcoholic steatohepatitis (NASH) are some of the biggest public health challenges due to their spread and increasing incidence around the world. NAFLD is characterized by intrahepatic lipid deposition, accompanied by dyslipidemia, hypertension, and insulin resistance, leading to more serious complications. Among the various causes, drug administration for the treatment of numerous kinds of diseases, such as antiarrhythmic and antihypertensive drugs, promotes the onset and progression of steatosis, causing drug-induced hepatic steatosis (DIHS). Here, we reviewed in detail the major classes of drugs that cause DIHS and the specific molecular mechanisms involved in these processes. Eight classes of drugs, among the most used for the treatment of common pathologies, were considered. The most diffused mechanism whereby drugs can induce NAFLD/NASH is interfering with mitochondrial activity, inhibiting fatty acid oxidation, but other pathways involved in lipid homeostasis are also affected. PubMed research was performed to obtain significant papers published up to November 2021. The key words included the class of drugs, or the specific compound, combined with steatosis, nonalcoholic steatohepatitis, fibrosis, fatty liver and hepatic lipid deposition. Additional information was found in the citations listed in other papers, when they were not displayed in the original search.
\end{abstract}

Keywords: drug-induced hepatic steatosis (DIHS); NAFLD; NASH; mitochondrial dysfunction

\section{Introduction}

Non-alcoholic fatty liver disease (NAFLD), which includes both non-alcoholic fatty liver (NAFL) or simple steatosis and its progression to non-alcoholic steatohepatitis (NASH), is considered the hepatic manifestation of a condition called "metabolic syndrome", which comprises a wide spectrum of metabolic abnormalities, such as simple steatosis, dyslipidemia, hypertension, insulin resistance and diabetes [1,2]. However, NAFLD is not always associated with metabolic syndrome. Exome-wide association studies demonstrated that the genetic variants located in 148Met allele of PNPLA3 and 167Lys allele of TM6SF2 genes are strictly associated with increased hepatic lipid deposition, steatohepatitis, cirrhosis and hepatocellular carcinoma, reducing at the same time the triglyceride plasma levels, the LDL-cholesterol concentrations and the risk of coronary artery disease [3]. In particular, the 148Met variant inhibits the proteasome-dependent degradation of PNPLA3, which accumulates and causes a decreased mobilization of triglycerides from the liver and a reduction in blood triglycerides concentration [4]. As regards the 167Lys variant allele in TM6SF2 gene, instead, it has been proposed to be responsible for the accumulation of toxic cholesterol in the liver and adipose tissue, moving it away from the blood vessels and protecting from cardiovascular diseases, but causing liver and adipose dysfunction [5]. Recently, some hepatologists proposed to replace the term NAFLD with metabolic associated 
fatty liver disease (MAFLD); however, at the moment, the nomenclature is still unchanged because the molecular bases and implications of the name switch are not fully understood; in addition, a premature change might create confusion [6], mainly because many clinical trials are currently specifically targeting NASH, which is not a major aspect in the concept of MAFLD. About a quarter of the world population suffers from NAFLD [7], characterized by intrahepatic lipid accumulation, with rates exceeding $43 \%$ in patients with metabolic syndrome [8]. Fortunately, only about $10 \%$ of patients suffering from NAFLD progress to $\mathrm{NASH}$, even if this percentage is much higher in patients suffering from diabetes (37.7\%), who present at the same time the highest prevalence rate of NAFL (55.5\%), among the most important accompanying diseases [9]. In NASH, the hepatic fat deposition is accompanied by inflammation and increased free fatty acid oxidation, which can lead to a high risk of fibrosis, cirrhosis, and hepatocellular carcinoma development $[10,11]$.

Among the various causes inducing steatosis and steatohepatitis, it has been estimated that a small percentage of cases, around $2 \%$, are related to drug administration [12]. Druginduced liver injury (DILI) associated with the onset and progression of NAFLD/NASH is known as drug-induced hepatic steatosis (DIHS). Many drugs are able to produce this side effect, including: antiarrhythmic drugs, antihypertensive drugs, anti-epileptic drugs and antineoplastic drugs. Generally, DIHS occurs in individuals who are genetically predisposed to develop steatosis, or who exhibit primary risk factors or comorbidities. DIHS has been described as a chronic disorder associated with therapies prolonged by weeks or months, but reversible after dismissing the treatment when it is possible [13]. In some cases, as in patients affected by acquired immune deficiency syndrome (AIDS) and subjected to highly active antiretroviral therapy (HAART) such as zidovudine, liver abnormalities are established and they may lead to death because of severe lipid dysregulation and accumulation, steatohepatitis, and acidosis [14-17]. Normally, livers already affected by steatosis are more prone to developing DIHS and, if this condition is concomitant with low hepatic energy production, the drugs can easily interfere with mitochondrial function, leading to further hepatic damage [13]. For this reason, many authors distinguish drugs able to induce steatosis and steatohepatitis into three categories: drugs that precipitate latent or already existing NASH as tamoxifen; drugs that can cause steatosis and steatohepatitis per se, such as the antiarrhythmic drugs amiodarone and perhexiline; drugs that induce sporadic events of NAFLD/NASH as carbamazepine [18]. The major mechanisms whereby drugs can induce NAFLD/NASH, as already mentioned, are by interfering with mitochondrial activity, inhibiting fatty acid oxidation, oxidative phosphorylation, and mitochondrial respiration [18]. However, NAFLD can be induced not only by mitochondrial dysfunction and inhibition of fatty acid oxidation, but also by dysregulation of lipid hepatic homeostasis in terms of fatty acid uptake, de novo lipogenesis (DNL), and transport by very low density lipoprotein (VLDLs) [19]. Thus, to better understand DIHS, it would be useful to briefly summarize the molecular mechanisms involved in the onset of hepatic steatosis, because many drugs can affect in different ways all of these processes. The aim of this work was precisely to provide a detailed picture of all the molecular mechanisms involved in drug-induced steatosis for eight different classes of compounds.

\section{Molecular Mechanisms Involved in NAFLD Onset}

Usually, an increase in hepatic lipid uptake and DNL occurs with a concomitant compensatory increment of fatty acid oxidation (FAO)) that, sometimes, is not sufficient to restore the normal content of lipids resulting in lipid accumulation. The consequent event is the initiation of hepatic damage and NAFLD progression triggered by oxidative stress, which leads to mitochondrial dysfunction and peroxisomal and cytochromes oxidation. Moreover, initially, the lipid export increases counteracting the fatty acid accumulation, but, at a certain point, this process reaches a plateau or even decreases during the disease progression, further promoting lipid accumulation [20].

A dysregulation of fatty acid uptake and in particular of the expression of specific transporters, such as: fatty acid transport protein (FATP), cluster of differentiation 36 
(CD36), and caveolins, represents the first step of hepatic lipid accumulation. Knockdown and knockout mice for FATP2 and FATP5 showed a decreased fatty acids uptake and reduced hepatic steatosis after high-fat diet administration [21,22]; similarly, deletion of CD36 gene in mouse livers produced the same result [23]. Patients diagnosed with NAFLD or NASH, in fact, showed increased gene and protein expression of CD36, when compared with healthy controls [24], demonstrating the important role of this transporter in lipid accumulation.

The liver can also synthesize lipids itself through DNL starting from acetyl-CoA, which is converted into malonyl-CoA by acetyl-CoA carboxylase (ACC). Malonyl-CoA becomes the substrate of fatty acid synthase (FAS) to produce palmitate. Many enzymes, such as desaturases [1] and elongases, rearrange the new fatty acid before its final esterification into triglyceride or exportation as VLDL. This process is finely regulated by two transcription factors: sterol regulatory element-binding protein 1c (SREBP-1c) and carbohydrate regulatory element-binding protein (ChREBP); SREBP-1c is activated by increased insulin and lipids, while ChREBP is regulated by increased carbohydrates [20]. NAFLD patients display abnormally elevated DNL when compared with healthy individuals [25]; in obese patients with NAFLD, about $26 \%$ of hepatic triglycerides come from DNL. In addition, in these patients, the regulation of DNL is lost when they pass from a fasting to a fed state [26].

The fate of fatty acids entering the hepatic cell is to form triglyceride stores, or to be oxidized to obtain energy in the form of ATP, in particular when circulating glucose levels are low. Oxidation of fatty acids occurs mainly in mitochondria, where the carnitine palmitoyltransferase 1 (CPT1) allows their entry, but it can also occur in peroxisomes and cytochromes, by $\beta$ - and $\omega$-oxidation, respectively. Regardless of where it occurs, FAO is regulated by peroxisome proliferator-activated receptor (PPAR)- $\alpha$ transcription factor activity $[27,28]$. PPAR $\alpha$ activity promotes the transcription of genes related to mitochondrial, peroxisomal and cytochrome-mediated FAO as medium- and long-chain acyl-CoA dehydrogenases, acyl-CoA oxidase (ACOX) 1 and enoyl-CoA hydratase, CYP4A1 and CYP4A3, respectively, as demonstrated in PPAR $\alpha$ deficient ob/ob mice [29]. In NASH patients, PPAR $\alpha$ is downregulated and its expression decreases concomitantly with the increase in NAFLD activity score and fibrosis grade [30]. However, enhanced FAO produces a considerable quantity of ROS, which promotes inflammation and so the progression of the disease [31]. In this situation, a vicious circle is established: lipid oxidation and consequently ROS production induces mitochondrial DNA damage, further decreasing the mitochondrial activity and leading to their dysfunction [28], as reported in NASH overweight/obese patients [32,33].

Lastly, lipid export is also affected in the setting of NAFLD. In the endoplasmic reticulum (ER), VLDL particles are produced by lipidation of apolipoprotein B100 (apoB100), a process catalyzed by the microsomal triglyceride transfer protein (MTTP). The product is transferred to the Golgi apparatus, where a second lipidation is required for the maturation of the VLDL particle [34]. In NASH patients, levels of apoB100 and MTTP may be diminished leading to a limited VLDL export, further exacerbating lipid accumulation [20] (Figure 1). 


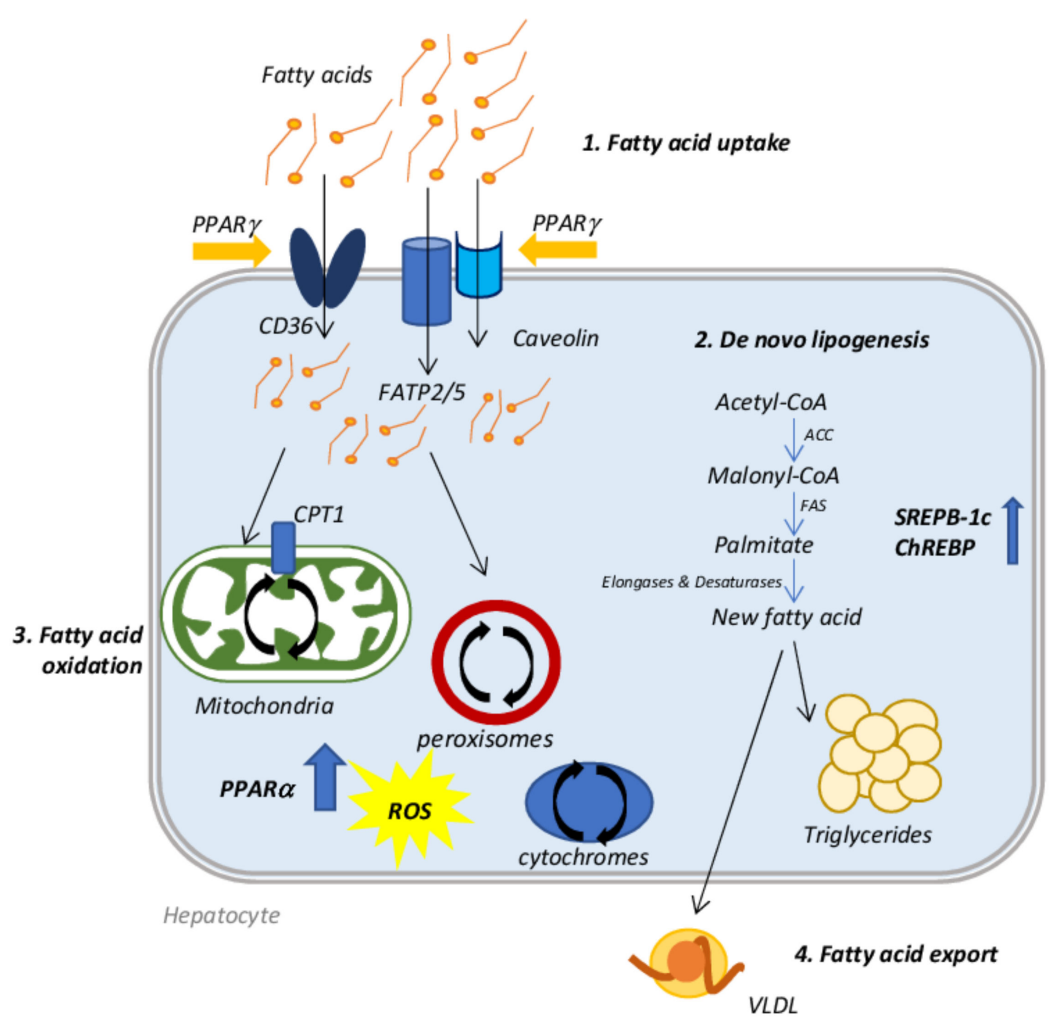

Figure 1. Schematic representation of the molecular mechanisms involved in NAFLD onset. 1. Fatty acid uptake: fatty acids are introduced in the cell by specific transporters such as CD36, FATP2/5 and caveolins, which are controlled by PPAR $\gamma$ transcriptional activity. 2 . De novo lipogenesis: the liver synthesizes fatty acids starting from acetyl CoA. This mechanism is controlled by ChREBP and SREBP-1c activity. The new fatty acid can be stored as triglycerides or exported via VLDL formation. 3. Fatty acid export: VLDL particles are produced by lipidation of apoB100 in the ER and then they are transferred to the Golgi apparatus for a second lipidation that is necessary for maturation and export. 4. Fatty acid oxidation: Fatty acids introduced from the external environment or produced by de novo lipogenesis can be oxidized to form energy by mitochondrial and peroxisomal $\beta$-oxidation and by cytochrome $\omega$-oxidation. All these processes produce ROS.

\section{Drugs Inducing Hepatic Steatosis}

The major drugs involved in steatosis onset are listed in the table below (Table 1).

Table 1. List of the major drugs involved in steatosis onset and progression. They are classified according with their clinical use; their mechanisms of steatosis induction are also indicated.

\begin{tabular}{|c|c|c|}
\hline Drug & Category & Mechanisms \\
\hline Amiodarone & antiarrhythmic & $\begin{array}{c}\text { Inhibition of OXPHOS, FAO, CPT1 } \\
\text { Inhibition of MRC complex I and III } \\
\text { Induction of ER stress } \\
\text { Upregulation of SREBP-1c, ACLY, FAS, SCD1 }\end{array}$ \\
\hline Perhexiline & antiarrhythmic & $\begin{array}{l}\text { Inhibition of OXPHOS, FAO, CPT1 } \\
\text { Inhibition of MRC complex I and III }\end{array}$ \\
\hline Diltiazem & antiarrhythmic & $\begin{array}{c}\text { Conflicting data: observed steatosis with no described } \\
\text { molecular mechanism }\end{array}$ \\
\hline Verapamil & antiarrhythmic & $\begin{array}{l}\text { Conflicting data: observed steatosis but also reduced } \\
\text { inflammation, collagen deposition, lipid peroxidation, } \\
\alpha \text {-SMA and TGF } \beta 1\end{array}$ \\
\hline
\end{tabular}


Table 1. Cont.

\begin{tabular}{|c|c|c|}
\hline Drug & Category & Mechanisms \\
\hline Losartan & antihypertensive & $\begin{array}{c}\text { Amelioration of NAFLD: reduced markers of } \\
\text { hepatic fibrosis }\end{array}$ \\
\hline Enalapril & antihypertensive & $\begin{array}{c}\text { Macro- and microvesicular steatosis with increased } \\
\text { inflammation }\end{array}$ \\
\hline Nifedipine & antihypertensive & $\begin{array}{c}\text { Conflicting data are reported: } \\
\text { increased enzyme release, macro- and microsteatosis } \\
\text { with fibrosis; } \\
\text { upregulation of PPAR } \gamma \text { receptor with consequent } \\
\text { reduction in NASH, fibrosis and AST release }\end{array}$ \\
\hline Tetracyclines & antibiotic & $\begin{array}{c}\text { Inhibition of FAO (PPAR } \alpha, \text { CPT1), inhibition of lipid } \\
\text { export, } \\
\text { Upregulation of fatty acid transport, } \\
\text { Upregulation of CYP2E1 and ROS production }\end{array}$ \\
\hline Linezolid & antibiotic & Inhibition of mtDNA translation and OXPHOS activity \\
\hline Rifampicin & antibiotic & $\begin{array}{l}\text { Upregulation of de novo lipogenesis (SCD1, ACC, FAS), } \\
\text { Upregulation of fatty acid uptake (PXR, PPAR } \gamma, C D 36), \\
\text { Inhibition of FAO }\end{array}$ \\
\hline Tamoxifen & antineoplastic & $\begin{array}{l}\text { Inhibition of FAO through ER } \alpha / \beta \text { receptors, } \\
\text { Inhibition of mtDNA synthesis, } \\
\text { Conflicting data: downregulation of FAS, but also } \\
\text { induction of SREBP-1c }\end{array}$ \\
\hline Toremifene & antineoplastic & Few cases of steatosis \\
\hline Irinotecan & antineoplastic & $\begin{array}{c}\text { Decrease in mtDNA synthesis, } \\
\text { Inhibition of OXPHOS, } \\
\text { Mitochondrial dysfunction, inflammation and fibrosis }\end{array}$ \\
\hline 5-Fluorouracil & antineoplastic & $\begin{array}{c}\text { Increase in triglyceride accumulation, } \\
\text { Mitochondrial dysfunction, } \\
\text { Increase in peroxisomal beta-oxidation and ROS } \\
\text { generation, } \\
\text { Induction of JNK, IL-8 and ICAM.-1 }\end{array}$ \\
\hline L-Asparaginase & antineoplastic & $\begin{array}{l}\text { Mitochondrial dysfunction, } \\
\text { Alteration in VLDL secretion and metabolism, }\end{array}$ \\
\hline Methotrexate & antineoplastic a & $\begin{array}{l}\text { Decrease in OXPHOS, } \\
\text { Downregulation of mitochondrial enzymes, } \\
\text { Depletion of folate mitochondrial stores, } \\
\text { Activation of stellate cell A2A receptor, leading to fibrosis }\end{array}$ \\
\hline Valproic acid & antiepileptic & $\begin{array}{c}\text { Acyl CoA sequestration and mitochondrial } \\
\text { FAO inhibition, } \\
\text { Reduction in citric acid cycle flux, } \\
\text { Inhibition of OXPHOS, } \\
\text { Inhibition of ATP production, } \\
\text { Upregulation of CD36, } \\
\text { Increase in oxidative stress and decrease in } \\
\text { antioxidant defenses }\end{array}$ \\
\hline Carbamazepine & antiepileptic & $\begin{array}{l}\text { Decrease in microsomal cytochrome P-450 dependent } \\
\text { enzyme activity }\end{array}$ \\
\hline Dexamethasone & glucocorticoid & Hyperphagia (inhibition of leptin signaling pathway), \\
\hline Betamethasone & glucocorticoid & Increase in de novo lipogenesis, \\
\hline Prednisolone & glucocorticoid & $\begin{array}{c}\text { upregulation of CD36, } \\
\text { decreased secretion of VLDL, }\end{array}$ \\
\hline Triamcinolone & glucocorticoid & decreased FAO \\
\hline
\end{tabular}


Table 1. Cont.

\begin{tabular}{|c|c|c|}
\hline Drug & Category & Mechanisms \\
\hline $\begin{array}{l}\text { Salicylic acid } \\
\text { (Aspirin) }\end{array}$ & NSAID & $\begin{array}{l}\text { Conflicting data: mitochondrial dysfunction, } \\
\text { increase in eNOS and decrease in iNOS and TNF- } \alpha \text {, } \\
\text { reduction in JNK activity }\end{array}$ \\
\hline Acetaminophen & NSAID & $\begin{array}{c}\text { Increase in ROS generation, } \\
\text { Mitochondrial damage, } \\
\text { GSH depletion, } \\
\text { Accumulation of long-chain acylcarnitines, } \\
\text { Reduction in PPAR } \alpha \text { expression, } \\
\text { Alteration of FAO }\end{array}$ \\
\hline Pirprofen & NSAID & Inhibition of FAO and natural CoA activity \\
\hline Ibuprofen & NSAID & Inhibition of FXR transcriptional activity \\
\hline Diclofenac & NSAID & Inhibition of mtFAO \\
\hline Naproxen & NSAID & Inhibition of mtFAO \\
\hline Ketoprofen & NSAID & $\begin{array}{l}\text { Inhibition of mitochondrial function, } \\
\text { ROS accumulation }\end{array}$ \\
\hline $\begin{array}{l}\text { Zidovudine } \\
\qquad(\mathrm{AZT})\end{array}$ & NRTI & $\begin{array}{c}\text { Inhibition of DNA polymerase } \gamma, \\
\text { ER stress induction, } \\
\text { Increase in SREBP-1c, } \\
\text { Decrease in PPAR } \alpha \text {, phospho-AMP kinase and } \\
\text { 3-keto-acyl-CoA thiolase, } \\
\text { Inhibition of autophagy }\end{array}$ \\
\hline Stavudine & NRTI & $\begin{array}{l}\text { Inhibition of DNA polymerase } \gamma, \\
\text { Inhibition of autophagy }\end{array}$ \\
\hline Didanosine & NRTI & $\begin{array}{c}\text { Inhibition of DNA polymerase } \gamma \text {, } \\
\text { Inhibition of oxygen consumption and complex I and } \\
\text { III activity }\end{array}$ \\
\hline
\end{tabular}

\subsection{Antiarrhythmic Drugs}

Among the drugs listed in the category of antiarrhythmic agents, it is known that amiodarone and perhexiline can induce hepatic steatosis in a similar way.

Amiodarone belongs to the class III antiarrhythmic drugs; it is a complex compound that shows multiple electrophysiologic properties, unusual pharmacokinetics and various risky interactions and side effects. It has only been approved to treat life-threatening ventricular arrhythmias, but actually it is also used to treat atrial fibrillation [35]. Amiodarone is an iodine-containing compound similar to thyroxine and it is stored at high concentration in muscles, liver, lung and skin. It is lipid soluble and, probably, its prolonged half-life could be due to its slow release from tissues rich in lipids [36].

Perhexiline is an antianginal agent with few effects on blood pressure and heart rate, compared with other antianginal compounds [37]. It has a controversial history: because of a small number of cases of severe hepatotoxicity and neurotoxicity it was removed from the market in 1988, currently prescribed only in Australia and New Zeeland when no other option is available [38].

Both these drugs can induce hepatic lesions with a similar mechanism. In fact, they are both lipophilic compounds when they are in neutral form, but in their structure is present a secondary or tertiary amine that can be protonated, transforming these drugs into amphiphilic cations [39]. Prolonged and repeated administration of amiodarone and perhexiline can induce symptomatic liver disease in a small percentage (1-3\%) of patients, which develop both micro- and macrosteatosis [40], with histopathological features resembling the alcohol-induced liver injury $[40,41]$. In particular, hepatocyte ballooning, Mallory Denk bodies and fibrosis are observed, accompanied by nuclear disorders, acidophilic bodies, foamy cells, glycogenated nuclei and portal hypertension. Moreover, after acute 
amiodarone administration, intracytoplasmic lamellar bodies were found in the hepatocytes, representing phospholipidosis [42,43]; the same lesions are typical of perhexiline administration [39]. Many mechanisms are involved in amiodarone and perhexiline induced microsteatosis and in particular, it has been demonstrated that they can inhibit both oxidative phosphorylation (OXPHOS) and mitochondrial fatty acid $\beta$-oxidation (FAO) [44]. When amiodarone or perhexiline, due to their amphiphilic properties, enter the intermembrane space of mitochondria, they undergo a protonation, generating cationic derivatives that freely enters the mitochondrion thanks to a favorable transmembrane potential [39,40]. This event has two consequences: these drugs rapidly and transiently uncouple the OXPHOS and, at the same time, the accumulation of cationic derivatives in the mitochondrial matrix causes the inhibition of different enzymes of the mitochondrial respiratory chain (MCR) and of FAO [44,45]. Whereas low concentrations of amiodarone and perhexiline can induce direct inhibition of FAO enzymes as CPT1 [44], higher concentrations are needed to impair MRC activity at the level of complexes I and II, as demonstrated by Fromenty et al. in 1990, using isolated liver mitochondria from mice exposed to $200 \mu \mathrm{M}$ of amiodarone. The authors suggested that hydrophobic interactions of amiodarone with proteins and/or phospholipids of the inner membrane might be involved in the onset of these damages [46]. More recently, Spaniol and colleagues demonstrated on isolated rat liver mitochondria that amiodarone toxicity is related to the benzofuran structure and that also the complex III of the respiratory chain is affected [47]. It has been proposed that a moderate impairment of MRC activity could be involved in the transition from steatosis to steatohepatitis by means of an increase in ROS generation from complexes I and III [48]. ROS overproduction triggers lipid peroxidation and many other deleterious effects on the liver [44,49]. Moreover, it has been demonstrated that patients with specific CYP2D6 polymorphisms are at greater risk of developing steatohepatitis when administered with perhexiline, since CYP2D6 is the major enzyme in perhexiline metabolism [50].

A recent study by Erez et al. demonstrated in immortalized hepatocytes and in mice, that amiodarone administration strongly increases the expression of the spliced X-box binding protein 1 (sXBP1) and of its downstream target proteins, in particular CCAATenhancer-binding protein homologous protein $(\mathrm{CHOP})$, markers of the endoplasmic reticulum (ER) stress response [51]. A possible explanation of the ER stress induction could be referred to the decrease in $\mathrm{Ca}^{2+}$ levels in the ER compartment, due to the amiodarone inhibition of mitochondrial respiration and to the ATP depletion, causing the reduced activity of the smooth endoplasmic reticulum $\mathrm{Ca}^{2+}$ pump (SERCA). This event induces the $\mathrm{CHOP}$ activation, which contributes to lipid accumulation by activating the lipid droplet proteins cell death activator (Cidea), cell death inducing DFFA like effector $\mathrm{C}$ (Cidec), and perilipin-2 (Figure 2). These data are supported by studies in CHOP-deficient mice, which are less susceptible to amiodarone-induced steatosis [51] and by the study of Kudo et al., in which the administration of 1-(3,4-dihydroxyphenyl)-2-thiocyanate-ethanone (Bix), an enhancer of the ER stress element response, was able to decrease ER stress [52]. With this information, Erez and colleagues demonstrated that Bix administration reduced the amiodarone-induced lipid accumulation by the decrease in sXBP1, CHOP, Cidea and Cidec protein expression in mice $[51,53]$.

Lastly, a wealth of evidence demonstrated that amiodarone induces macrovesicular steatosis upregulating many genes related to lipogenesis, although the specific mechanism of this process remains unknown. In particular, transcripts of SREBP-1, ATP-citrate synthase (ACLY), fatty acid synthase (FAS) and acyl-CoA desaturase 1 (SCD1) were significantly overexpressed after acute or prolonged ( $24 \mathrm{~h}$ or 14 days) amiodarone exposure in HepaRG cells [43]. 


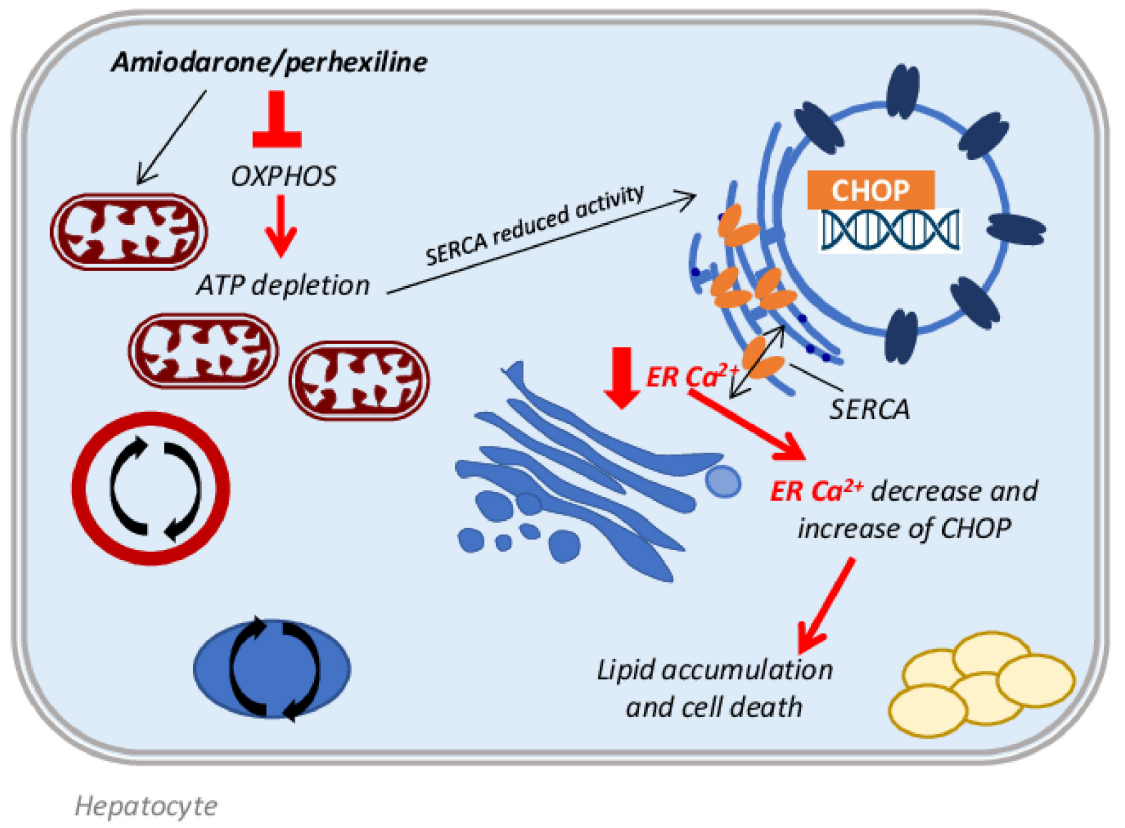

Figure 2. Schematic representation of one of the molecular mechanisms involved in amiodarone/perhexiline-induced NAFLD. The ATP depletion caused by amiodarone/perhexiline interference with OXPHOS leads to the reduced activity of the smooth endoplasmic reticulum $\mathrm{Ca}^{2+}$ pump (SERCA). The reduction in $\mathrm{ER} \mathrm{Ca}^{2+}$ produces ER stress and the upregulation of CHOP activity with consequent increase in the activity of the lipid droplet proteins cell death activator (Cidea), cell death inducing DFFA like effector C (Cidec), and perilipin-2, which are involved in lipid accumulation.

As regards other antiarrhythmic drugs, such as diltiazem and verapamil, two calcium channel blockers, the data available at present are unclear. Some authors reported that both these drugs are able to induce steatosis in some patients [13,48], but no specific molecular mechanisms have been elucidated yet; therefore, the evidence supporting that diltiazem and verapamil induce steatosis is weak and controversial. In particular, many studies suggested a protective effect of verapamil in different kinds of hepatic damage. For example, Zhou and colleagues showed that intraperitoneal injection of verapamil $25 \mathrm{mg} / \mathrm{kg} /$ day for 7 days was able to reduce meta-inflammation, hepatic steatosis and insulin resistance, inhibiting the activation of thioredoxin-interacting protein (TXNIP)/nod-like receptor protein 3 (NLRP3) inflammasome, in mice subjected to a high-fat diet for 10 weeks [54]. Furthermore, in rats fed by high fat diet and 10\% ethanol in drinking water, treated with subcutaneous injection of carbon tetrachloride $\left(\mathrm{CCl}_{4}\right)$ to rapidly induce fibrosis, the intragastric administration of 20,40 and $80 \mathrm{mg} / \mathrm{kg} /$ day of verapamil significantly reduced all markers of liver injury and fibrosis such as lipid peroxidation, collagen deposition, $\alpha$-smooth muscle actin ( $\alpha$-SMA) and transforming growth factor- $\beta 1$ (TGF $\beta 1$ ) protein expression [55]. Therefore, in light of these data, further studies are needed to better clarify the actual role of verapamil and diltiazem in liver damage.

\subsection{Antihypertensive Drugs}

It is well known that hypertension is often associated with metabolic syndrome with all its manifestation including hepatic steatosis [56]. In particular, recent studies showed a significant interplay between the renin-angiotensin-aldosterone system (RAAS) and NAFLD, demonstrating that hypertension and NAFLD share common pathophysiological pathways. Angiotensin II (Ang II), in fact, promotes insulin resistance, which plays a great part in the onset and progression of NAFLD [57]. Bataller and colleagues showed that human hepatic stellate cells, after activation, synthesize Ang II, promoting the tissue 
remodeling in the liver [58]. Many studies confirmed that Ang II produced in fibrotic livers stimulates myofibroblast and hepatic stellate cell proliferation, inflammatory cell infiltration and cytokine and growth factor release, such as IL-1 $\beta$, monocyte chemoattractant protein-1 (MCP-1), TGF $\beta$ and connective tissue growth factor [59]. In support of this argument, the infusion of Ang II in a rat model of bile duct ligation increased liver fibrosis and inflammation [60], while RAAS inhibitors administration in animal models of fatty liver attenuated the progression of NAFLD [61-63].

Evidence was found in the literature demonstrating the beneficial effects of antihypertensive therapy on NAFLD. For example, losartan, an angiotensin II receptor antagonist used to treat hypertension, showed beneficial effects after 48 weeks of treatment $(50 \mathrm{mg} / \mathrm{d})$ in eight hypertensive patients with $\mathrm{NASH}$, leading to a significant decrease in various markers of hepatic fibrosis. In particular, TGF $\beta 1$, serum ferritin concentration and serum aminotransferase levels were decreased by losartan administration. The necroinflammation ameliorated in five patients, a reduction in hepatic fibrosis was observed in four patients and iron deposition disappeared in two patients; no side effects were detected in any patient [64].

However, many other antihypertensive agents have been reported to cause liver injuries, even though the precise mechanism involved in the onset of hepatic damage is not clear. Enalapril (ELP) is an angiotensin-converting enzyme (ACE) inhibitor, which is commonly employed for the treatment of cardiovascular diseases, including hypertension and heart failure [65]. It has been reported that mice treated with ELP alone did not develop liver injury. Differently, the combined treatment of ELP with the synthetic glucocorticoid dexamethasone (DEX) and the glutathione synthesis inhibitor L-buthionine$(\mathrm{S}, \mathrm{R})$-sulfoximine (BSO) resulted in liver steatosis with increased levels of plasma alanine aminotransferase (ALT), accompanied by myeloperoxidase-positive cells infiltrating hepatic tissue and increased oxidative stress-related factors, such as hepatic heme oxygenase- 1 , serum hydrogen peroxide and hepatic malondialdehyde [65]. Moreover, in a clinical case report, ELP was suspected to induce macro- and microvesicular steatosis in association with neutrophil infiltration and Mallory body formation with satellitosis; the patient had a 10-year history of systemic lupus erythematosus, was under corticosteroid therapy for one year (40 mg/day) and taking ELP (10 mg/day) for 2.5 years to treat hypertension. The hepatic alterations were distributed mostly in zone 1 of the periportal region and less commonly in zone 2 and 3 . The extensive periportal necrosis and fibrin deposits, in association with inflammatory cells infiltration, made the clinical features of this patient very close to periportal steatohepatitis, although it was different from both the alcohol-induced and non-alcoholic induced ones, which spread from zone 3 to other zones [66].

As regards nifedipine, a calcium channel blocker, conflicting data emerged from the literature. Babany et al. described, in a clinical case report, the development of steatosis associated with Mallory bodies in a female patient treated with nifedipine and already under treatment with colchicine for gout, with hydroxycarbamide for thrombocythemia and with clonidine for arterial hypertension. After two months of treatment with nifedipine, serum enzymes such as alkaline phosphatase (ALP) and $\gamma$ GT were significantly increased and the liver biopsy showed extensive fibrosis in the portal tracts, micro- and macrovacuolar steatosis affected 50\% of the hepatocytes, hepatocyte ballooning and refringent heterogenous clumps were identified as Mallory bodies. After stopping nifedipine administration, all lesions disappeared after one month, without the suspension of other treatment [67]. On the contrary, Nakagami et al. demonstrated that nifedipine, acting as an activator of the PPAR $\gamma$ receptor, reduced NASH in a rat model of methionine and choline deficient (MCD) diet. In fact, rats fed by an MCD diet supplemented by nifedipine for 20 weeks, showed a significant decrease in fibrosis and AST serum levels, when compared with rats fed by an MCD diet alone for the same period [68]. It is known that the activation of PPAR $\gamma$ in the liver is connected with fat deposition in the hepatic parenchyma, whereas the activation of adipose PPAR $\gamma$ protects against steatosis [69]. However, in this regard some clarifications are necessary. Studies by Miyahara et al. demonstrated that PPAR $\gamma$, in liver, is highly 
expressed in quiescent hepatic stellate cells (HSC) and that it is downregulated during HSC activation. The administration of PPAR $\gamma$ agonist 15dPGJ2 in cultured activated HSC reduced collagen synthesis, whereas the co-administration of PPAR $\gamma$ agonist 15dPGJ2 with the PPAR $\gamma$ antagonist GW9662 abrogated 70\% of the collagen reduction obtained by the agonist alone, showing the potential therapeutic effect of PPAR $\gamma$ ligands in the treatment of liver fibrosis [70]. Similarly, Bae and colleagues demonstrated in HSC-T6 cells that the PPAR $\gamma$ agonist KR62776 administration caused HSC apoptosis, accompanied by a timeand concentration-dependent decrease in the alpha-smooth muscle actin levels, showing that PPAR $\gamma$ stimulation is strictly involved in limiting the activation and proliferation of HSC preventing liver fibrosis [71].

\subsection{Antibiotics}

Among antibiotics, many drugs are able to induce steatosis. For example, tetracycline, a broad-spectrum antibiotic employed to treat various infections of the skin, soft tissues and upper respiratory tract, may induce hepatic steatosis both in humans and in rodents [72]. The family of tetracyclines counts many compounds similar to tetracycline, such as doxycycline, minocycline, methacycline and lymecycline, which induce various types of hepatic injury, including cholestasis, necrosis and microvesicular steatosis [73]. In particular, tetracycline-induced microvesicular steatosis was already observed several decades ago, especially in association with parenteral administration $[40,48]$. The mechanism involved in the onset of tetracycline-induced steatosis involves the inhibition of fatty acid oxidation genes, such as PPAR $\alpha, C P T 1$ and fatty acid binding protein 1 [74,75], and the decrease in hepatic lipoprotein secretion via microsomal triglyceride transfer protein inhibition [76,77]. Moreover, recent studies demonstrated that tetracycline administration affects the expression of many genes associated with fatty acid transport and esterification $[43,78]$. In particular, Choi et al. demonstrated that $100 \mu \mathrm{M}$ tetracycline treatment for $24 \mathrm{~h}$ upregulates the expression of fatty acid transporter CD36 and diacylglycerol acyltransferase 2 (DGAT2) in HepG2 cells and primary rat hepatocytes, contributing to fatty acid intake and their esterification, leading to the development of steatosis. Similar results were obtained by the same authors in mice treated with $50 \mathrm{mg} / \mathrm{Kg} /$ day tetracycline: a significant increase in mRNA and protein levels of CD36 and DGAT2 was observed in livers from tetracycline-treated mice, accompanied by increased levels of hepatic enzymes (AST, ALT, $\gamma$ GT, ALP), serum triglycerides and cholesterol [79]. Furthermore, tetracycline as doxycycline and minocycline could play a role in the progression of steatosis by enhancing oxidative stress generation, via the activating transcription factor 4 (ATF4), which induces ROS generation by means of CYP2E1 upregulation, and the inhibition of the mammalian target of rapamycin (mTOR) [80]. Moreover, Deng et al. demonstrated that tetracycline administration in HepG2 cells produces the alteration of many proteins located in the mitochondria. Among them, the long-chain specific acyl-CoA dehydrogenase, which is one of the key enzymes regulating fatty acid $\beta$-oxidation [81]. Lastly, it has been proved that many tetracycline derivatives bind to the mitochondrial ribosomes so inhibiting mtDNA translation [73].

This last mechanism of action is also typical of another antibiotic, the oxazolidinone linezolid, which is used to treat multi drug-resistant pathogens such as Gram-positive Enterococcus faecium, Staphylococcus aureus and Mycobacterium tuberculosis [82]. Linezolid binds to a site on the bacterial 23S ribosomal RNA of the 50S subunit, which prevents the formation of a functional 70S initiation complex, so affecting protein synthesis [82]. At the same time, this mechanism can also target mammalian mitochondrial protein synthesis via its binding to mitochondrial ribosomes and causing clinical manifestations observed in patients with genetic defects of OXPHOS $[40,83]$. This occurs because mitochondrial mammalian ribosomes share some similarities with bacterial ribosomes at the level of the linezolid binding site $[82,84]$, so when the drug interacts with mammalian ribosomes it may affect mitochondrial protein synthesis, resulting in the reduction of the mitochondrial respiration chain activity [82,85-87] (Figure 3). This condition, after several weeks of treat- 
ment with linezolid, produces in many patients an increase in plasma transaminase levels as well as macro- and microvesicular steatosis and bile duct injuries $[48,83,85,88]$.

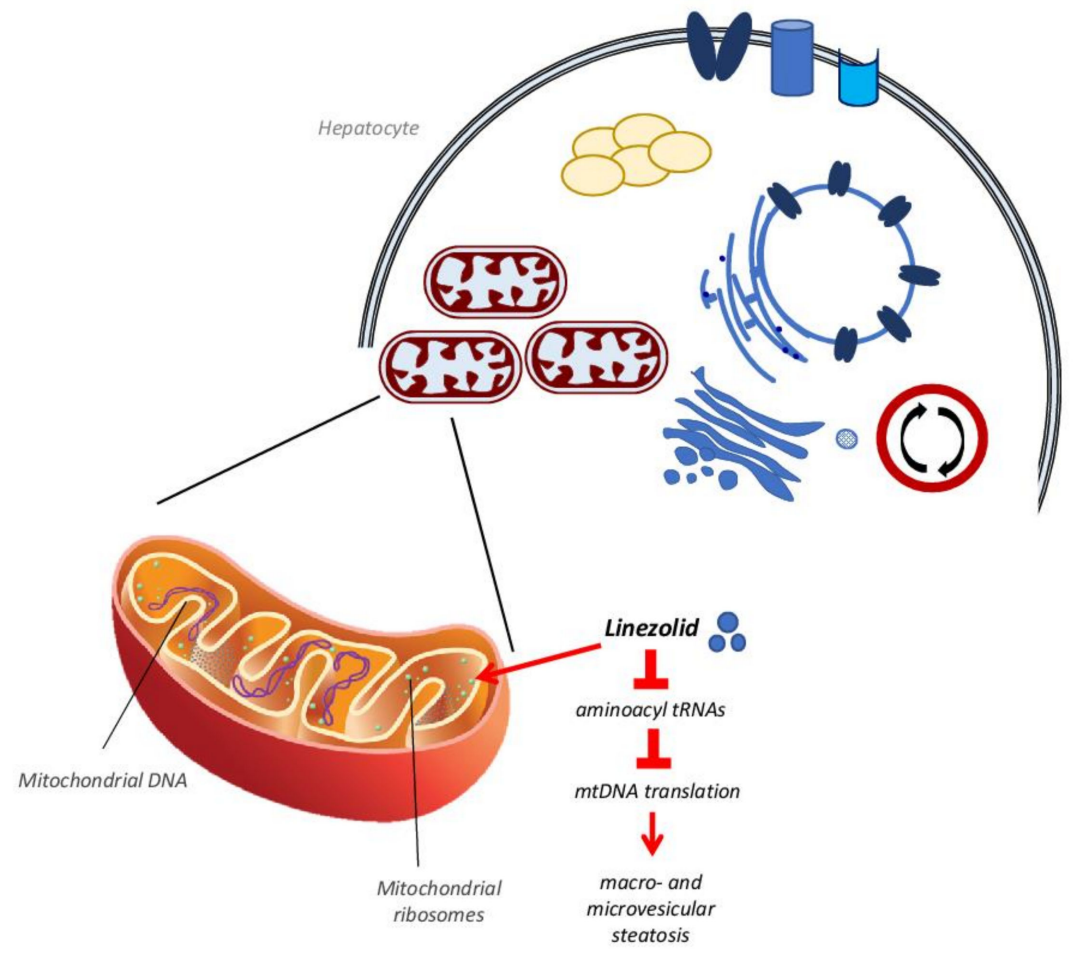

Figure 3. Linezolid activity on mitochondrial ribosomes. Linezolid stops the protein synthesis in bacteria by binding their ribosomes. At the same time, this drug can bind human mitochondrial ribosomes inhibiting the bond of aminoacyl tRNAs, blocking the mtDNA translation and reducing the mitochondrial respiration chain complexes activity. This process, after several weeks, produces micro and microvacuolar steatosis.

As regards rifampicin, an antibiotic drug largely used in the therapy of tuberculosis, it has been demonstrated that it can induce hepatic lipid accumulation. Huang et al. showed that after $200 \mathrm{mg} / \mathrm{Kg}$ /day administration of rifampicin, mice displayed increased serum levels of ALT and hepatic triglycerides already after 3 days of treatment; these parameters increased in a more significant way after 4 weeks of drug administration [89]. The authors demonstrated that rifampicin induces lipid hepatic accumulation through the upregulation of both fatty acid synthesis and hepatic lipid uptake. In particular, rifampicin administration was found to upregulate mRNA expression of SCD1, ACC and FAS, concomitantly with the upregulation of PXR and PPAR $\gamma$. In addition, it was also demonstrated that rifampicin upregulates CD36, hepatic FATP, a fatty acid transporter that participates in the uptake of long-chain fatty acids [90] and LDLR, a surface receptor that removes cholesterol-carrying LDL from plasma by receptor-mediated endocytosis [91]. Similar data were obtained by Allard et al., which demonstrated that rifampicin induces a dose-dependent lipid accumulation in HepaRG cells, through mtFAO inhibition [92].

\subsection{Antineoplastic Drugs}

Many antineoplastic drugs are able to induce DILI and DISH. Among them, tamoxifen is well known to induce hepatic steatosis and steatohepatitis. Tamoxifen is classified as an antagonist of the estrogen receptor and acts mainly in breast tissue. It is used as an adjuvant treatment for breast cancer and it decreases cancer recurrence and mortality in women with estrogen receptor-positive tumors [93,94]. It has been proven that about $40 \%$ of patients receiving long-term tamoxifen administration develop steatohepatitis [95]. The 
estimated time to the onset of steatosis following tamoxifen administration is approximately 22 months, but the steatosis incidence before 2 years of treatment is similar to the placebo, as demonstrated in a prospective, randomized, double blind, placebo-controlled trial, recruiting 5408 women subjected to hysterectomies from 58 centers in Italy. The $20 \mathrm{mg}$ /day tamoxifen administration was correlated with an increased risk of NASH development only in individuals who were overweight, or who showed obesity and metabolic syndrome [96]. In according with these results, many other studies reported that tamoxifen is a risk factor to develop steatosis when the patient is already affected by metabolic syndrome or diabetes [95-98]. As regards the mechanism of tamoxifen-induced hepatic steatosis, a lot of evidence, obtained both in animal models $[99,100]$ and in postmenopausal women treated with estrogens [101-103], demonstrated that estrogens play beneficial effects on liver metabolism, enhancing insulin sensitivity and preventing lipid accumulation and steatohepatitis. Thus, tamoxifen being an estrogen receptor antagonist, it promotes DISH [53]. In particular, it has been studied that this effect is strictly linked to the activity of estrogen receptor $\mathrm{ER} \alpha$; in fact, $\mathrm{ER} \alpha$ knockout mice showed lipid intrahepatic accumulation due to decreased insulin sensitivity [104]. On the contrary, the administration of ER $\alpha$ receptor agonists decreased steatosis in aromatase knockout mice [105]. The estrogen receptor $\mathrm{ER} \beta$ also seems to be involved in tamoxifen-induced steatosis; in fact, recent evidence demonstrated that the administration of the ER $\beta$ selective agonist isoquinolinone LGND2 prevented steatosis in mice fed by high-fat diet or by a methionine and choline deficient diet [106]. Moreover, a wealth of evidence demonstrated that estrogen receptors ER $\alpha$ and ER $\beta$ are also expressed on the mitochondrial surface [107]. Their activation can affect beta oxidation [108] upregulating specific genes such as PPAR $\alpha$ and PPAR $\gamma$, beta-3-hydroxyacyl CoA dehydrogenase (HADH $\beta), \mathrm{CPT} 1$ and pyruvate dehydrogenase kinase 4 (PDK4), as demonstrated in rats treated with estrogen [109]. In particular, Zhou et al. demonstrated that $\mathrm{ER} \alpha$ direct interaction with $\mathrm{HADH} \beta$ increases cellular beta oxidation and that tamoxifen inhibits this association leading, to a reduced beta oxidation rate [110]. Apart from its activity on estrogen receptors, other studies in mice revealed that tamoxifen accumulates in the mitochondrial matrix, impairing fatty acid oxidation, respiration, and mitochondrial DNA relaxation and synthesis due to its chemical properties as a DNA-intercalating and cationic amphiphilic compound [111]. Furthermore, Lelliot et al. demonstrated a tamoxifen-induced microvesicular steatosis and marked hypercholesterolemia in rats after only 5 days of treatment. In addition, tamoxifen downregulated fatty acid synthase (FAS) expression, as demonstrated by the accumulation of malonyl-CoA, causing the stop of fatty acid oxidation leading to steatosis [112]. On the contrary, more recent in vitro studies on HepG2 cells demonstrated that tamoxifen induction of macrovesicular steatosis is mediated by an enhancement of fatty acid synthesis through the induction of SREBP-1c and its downstream effectors, such as FAS, ACC and SCD [113]. Lastly, studies on breast cancer patients undergoing tamoxifen treatment demonstrated that there is an association between a particular polymorphism in the gene of cytochrome P450C17alpha, related to the circulating levels of estrogens, and the development of tamoxifen-induced hepatic steatosis [114].

Toremifene is another selective estrogen receptor modulator, also used as an adjuvant treatment for breast cancer. Toremifene is structurally similar to tamoxifen, apart from the substitution of a hydrogen atom with chlorine on the ethyl side chain; this change seems to be related to fewer thromboembolic events and reduced association with endometrial cancer [115]. As regards toremifene-induced steatosis and steatohepatitis, only a few cases of liver damage have been described after its administration. In particular, Hamada et al. demonstrated that only $7.7 \%$ of patients developed fatty liver after 3-5 years of toremifene administration. Moreover, toremifene-induced steatosis was less severe than that observed after tamoxifen administration; in addition, toremifene did not alter AST, ALT, $\gamma$ GT and total cholesterol serum levels [116]. The incidence of toremifene-induced NASH was also lower in comparison with tamoxifen [116]. 
Irinotecan is an antineoplastic compound often used in combination with other agents, as oxaliplatin, 5-fluorouracil (5-FU) and leucovorin, in the treatment of digestive cancers such as colorectal and pancreatic tumors. Its cytotoxic effect is due to its activity as a topoisomerase I complex inhibitor, which causes single-stranded DNA lesions and apoptotic cell death [94]. Unfortunately, one of the side effects of irinotecan is related to the development of steatohepatitis in about $20 \%$ of colorectal tumor patients treated with this compound before undergoing hepatic metastasis resection. This event results in a significant increase in 90-day post-operative mortality $[117,118]$. The mechanism whereby irinotecan induces steatohepatitis remains unknown, but it has been hypothesized that a mitochondrial dysfunction may be involved. In fact, irinotecan, like tamoxifen, intercalates into the mtDNA leading to the downregulation of enzymes involved in electron transport; in addition, as a cationic amphiphilic drug, it also uncouples the mitochondrial oxidative phosphorylation [18]. This situation is followed by an increase in ROS production, lipid peroxidation and beta-oxidation, which lead to the Kupffer cell-mediated release of proapoptotic cytokines, such as TNF- $\alpha$, and pro-fibrotic factors, such as TGF $\beta$, resulting in cell death, inflammation and fibrosis [119].

Additionally, 5-fluorouracil (5-FU) has been listed in the category of drugs able to induce steatosis. 5-FU is one of the most used anti-cancer compounds to treat digestive, head and neck, ovary and breast tumors. It is an anti-metabolite, in particular an anti-pyrimidine, which blocks the DNA and protein synthesis [94]. Similar to other antineoplastic compounds, it can cause lipid accumulation, especially in metastatic colorectal cancer patients, in which steatosis incidence range is registered between 30\% and 47\% [120]. Moreover, it has been demonstrated that 5-FU is related to chemotherapy-associated steatohepatitis $(\mathrm{CASH})$, which is often observed in patients treated with combined therapy of 5-FU and irinotecan [121-123]. Recently, the possible mechanism of the 5-FU-mediated induction of DISH has been elucidated by Sommer et al. These authors, using HepG2 cells and primary human hepatocytes, demonstrated that 5-FU induces a significant increase in hepatic triglyceride accumulation, accompanied by dysregulation of mitochondrial function and an increase in fatty acid acyl-CoA oxidase 1 (ACOX1), which represents the first step of the peroxisomal beta-oxidation. ACOX1 generates ROS, inducing the upregulation of the antioxidant enzyme heme oxygenase 1 (HMOX1) in 5-FU treated cells, followed by a significant increase in the activation of c-Jun N-terminal kinase (JNK) and of proinflammatory genes IL-8 and ICAM-1. The same authors obtained comparable data also in an in vivo model, showing that ACOX1 and HMOX1 upregulation, as well as JNKand pro-inflammatory gene expression and immune cell infiltration, induce NASH in mice [124]. Regarding the JNK trigger, recent studies demonstrated that an interplay between activated JNK (P-JNK) and mitochondria occurs through the SH3BP5 (SAB) protein. $\mathrm{SAB}$ is expressed in the mitochondrial outer membrane where it acts as a P-JNK docking protein and as a substrate of JNK [125]. JNK-induced SAB phosphorylation promotes mitochondrial dysfunction and ROS production and, as a feedback reaction, it activates the upstream mitogen-activated protein kinase (MAPK) pathway, which is the initial event in the P-JNK-mitoSAB-ROS activation loop [126-128]. In addition, studies in mice fed by high-fat, high calorie and high-fructose (HFHC) diet demonstrated a time-dependent increase in SAB expression, with the concomitant JNK activation [129]. The same authors also demonstrated that inducible hepatocyte specific SAB deletion (Sabi $\Delta \mathrm{Hep}$ ) in mice reduced significantly the JNK activation after 8 weeks of HFHC diet, accompanied by decreased body fat after 16 weeks. Similar data were obtained in 40-week-HFHC fed mice treated with SAB N-acetylgalactosamine antisense oligonucleotide (GalNAc-Sab-ASO) to obtain SAB knockdown mice. SAB knockdown mice, after 40 to 52 weeks of HFHC diet, showed a decreased steatohepatitis and fibrosis and restored SAB and P-JNK levels, with respect to those found in mice fed by standard diet, demonstrating the crucial role of P-JNK-mitoSAB-ROS loop in NASH [129].

Finally, it has been proposed that the onset of steatosis in patients treated with 5-FU could be attributed to the individual expression pattern of specific genes linked with 5- 
FU metabolism, in particular to decreased levels of dihydropyrimidine dehydrogenase (DPD) [130]. Presumably, some catabolites obtained by DPD activity, such as fluoro-betaalanine, remain after the interruption of 5-FU therapy in the hepatocytes and, saturating the metabolic pathway, causing the hepatic lipid accumulation [131].

The antineoplastic drug L-asparaginase is a protein-based enzyme obtained from Escherichia coli which hydrolyses asparagine, an amino acid not synthesized endogenously by leukemic cells, to aspartic acid and ammonia causing a decrease in asparagine serum levels [132] and therefore depriving cancer cells of this essential compound. It is employed to treat acute lymphoblastic leukemia and, like other anti-cancer agents, it is associated with the onset of hepatic steatosis in $40-87 \%$ of patients within 9 months after the first administration [94]. As regards the mechanism involved in the onset of L-asparaginase-induced steatosis, there is not much information available to date. There is some evidence showing that L-asparaginase may reduce protein synthesis and the level of both asparagine and glutamine, leading to hepatic micro- and macrovesicular steatosis [133-136]. In particular, Bodmer et al. in a clinical case report described a patient suffering from acute lymphoblastic leukemia and treated with L-asparaginase, which developed hepatic microvesicular steatosis accompanied by liver mitochondrial dysfunction and alterations in very-lowdensity lipoprotein (VLDL) metabolism and secretion [137]. The authors suggested that mitochondrial dysfunction could be attributed to the decreased hepatic protein synthesis, which is responsible for the lack of essential mitochondrial beta-oxidation proteins; in addition, the L-asparaginase-induced reduction in serum glutamine levels also was hypothesized to have a role $[134,135,138]$. In fact, glutamine is important for glutathione (GSH) synthesis and depletion of GSH stores is one of the leading causes of mitochondrial injury induced by oxidative stress in hepatocytes $[139,140]$. Moreover, in this case report a decrease in triglyceride serum levels, associated with low levels of VLDL, was found after L-asparaginase administration [137]. Probably, this change results from the asparaginase-induced inhibition of hepatic protein synthesis, which also may decrease the synthesis of microsomal triglyceride transfer protein (MTP), one of the key proteins in the VLDL formation and secretion mechanism, as demonstrated by Raabe et al.. In this paper, MTP knockout mice developed microvesicular steatosis caused by the absence of VLDL formation and secretion [141].

Methotrexate (MTX) is a folic acid antagonist employed as an antiproliferative and immunosuppressant agent in the treatment of malignancies and autoimmune diseases. It is employed in head, neck, bladder, lung, gynecologic cancers, lymphomas and leukemias; moreover, its use is recommended for the treatment of psoriatic and rheumatoid arthritis and in Crohn's disease [94]. It has been demonstrated that MTX induces lipid hepatic accumulation with a pathological pattern typical of alcohol-induced steatosis, mostly in patients chronically treated with low doses of MTX [53]. Moreover, in about $20 \%$ of patients, simple steatosis evolves into cirrhosis; to prevent this complication, guidelines recommend to perform a biopsy before and during the therapy with MTX [142], because it is one of the major causes of DISH. The mechanism by which MTX induces hepatic steatosis or cirrhosis is not completely clear; however, some evidence-based theories have been proposed. MTX affects oxygen uptake in the mitochondria, causing the decrease in oxidative phosphorylation [143]. MTX also downregulates many mitochondrial enzymes, such as 2-oxoglutarate, isocitrate, malate, and pyruvate dehydrogenases [144]. In addition, available data show that MTX induces the depletion of mitochondrial folate stores; in fact, it enters mitochondria and prevents the replenishment of folic acid [145]. Some evidence demonstrated that MTX, through ROS generation, impairs the mitochondrial membrane potential and induces apoptotic cell death by caspase activation [146], leading to mitochondrial dysfunction [147]. Moreover, Song et al. demonstrated that MTX induces steatohepatitis through its toxicity on the gastro-intestinal tract. Through the disruption of the intestinal barrier function, MTX favors bacterial translocation from the gut to the liver, as shown by rats treated with $3.5 \mathrm{mg} / \mathrm{kg}$ MTX for three days and then administered orally with E. coli expressing green fluorescent protein [148]. Lastly, it has been reported that MTX also 
induces fibrosis through the activation of the adenosine pathway. In particular, fibroblasts treated with $100 \mathrm{nM}$ MTX release a three-fold increased amount of adenosine [149], which over-activates the adenosine A2A receptor on the hepatic stellate cells, resulting in increased levels of collagen and downregulation of matrix metalloprotease activity [150].

\subsection{Antiepileptic Drugs}

Valproic acid (VPA) is an eight-carbon fatty acid molecule, administered as oral or parenteral formulations. VPA has been commonly applied in the treatment of epilepsy [151], both in adults and in children, since 1967. It has been estimated that more than one million people worldwide take VPA every day [152]. In fact, besides being the first line compound for newly identified epileptic disorders, it is also used to treat neuropathic pain, migraine [153], and bipolar disorder. Moreover, it is reported to be effective for spinal muscular atrophy [154], leukemia [155] and some solid tumors [156,157]. Nevertheless, VPA treatment can cause several adverse effects, such as dizziness, tremor, nausea, endocrinological disorders, obesity, insulin resistance, weight gain, and hepatotoxicity [158]. VPA is mainly metabolized at the hepatic level through three pathways: (i) glucuronidation, (ii) mitochondrial $\beta$-oxidation, (iii) cytochrome P450-mediated $\omega$-oxidation. These metabolic pathways produce about 50 known metabolites, some of which are biologically active and hepatotoxic [159]. VPA-induced hepatotoxicity is not easy to be diagnosed because patients are often asymptomatic. Even though VPA-hepatotoxicity has three clinical forms, which are hyperammonemia, acute hepatocellular injury and Reye-like syndrome, all of these forms present mitochondrial injury and microvesicular steatosis [160]. Several mechanisms have been suggested for VPA-induced hepatic steatosis. Both VPA and its metabolite 4-ene-VPA can sequester Acyl CoA, making it unavailable for $\beta$-oxidation. The complex VPA-CoA, by inhibiting the binding of both malonyl-CoA and palmitoyl-CoA to CPT1, attenuates fatty acid transport into mitochondria [161]. VPA also inactivates $\alpha$-ketoglutarate dehydrogenase, reducing citric acid cycle flux. Furthermore, high concentrations of VPA metabolites have an inhibitory effect on pyruvate uptake into rat liver mitochondria, preventing mitochondrial oxidative phosphorylation [162]. As a consequence, a 48-h VPA treatment has been associated with a reduction in the oxygen consumption rate, mitochondrial membrane potential and ATP levels in HepG2 cells. A prolonged VPA exposure not only decreases basal respiration rates in a collagen sandwich system of primary human hepatocytes [163], but it also favors lipid accumulation, due to the increased expression of the fatty acid transporter CD36 through epigenetic modification [164]. Besides mitochondrial damage, VPA administration correlates also with increased levels of oxidative stress and decreased antioxidant defense. On one hand, lipid hydroperoxide (LPO) and TBAR concentration increase in plasma and liver tissue in a VPA concentration-dependent way; on the other hand, VPA causes rapid hepatocyte GSH [165] and Nrf2 depletion [166]. Increased VPA-hepatotoxicity has been associated with genetic polymorphism of specific genes, including polymerase $\gamma$ gene (plog), glutathione S-transferase (gst), superoxide dismutase 2 (sod2), and metabolizing enzymes. Different approaches focused on the reduction of VPA hepatotoxicity are under investigation. For instance, it has been demonstrated in animal and clinical studies that L-carnitine supplementation may attenuate this adverse effect. Another strategy employed to neutralize VPA hepatotoxicity consists in the administration of pantothenic acid, a precursor of CoA. A protection against oxidative stress could be provided with antioxidants, such as N-acetylcysteine, a precursor of GSH, or zinc and selenium [167]. Recently, in VPA-induced NAFLD model in mice, both oxidative stress and steatogenic effect were reversed by the administration of obeticholic acid (OCA), a farnesoid X receptor (FXR) activator [168].

As regards other antiepileptic drugs, evidence does exist about their possible involvement in the onset of steatosis or steatohepatitis. For example, in a case report it has been shown that an epileptic woman, treated with carbamazepine for three months, developed both porphyria and steatohepatitis. The authors suggest that, in this case, the hepatic dysregulation of fatty acid content accompanied by inflammation may be due to the forma- 
tion of a carbamazepine toxic metabolite which impaired the mitochondrial membrane of hepatocytes, decreasing the microsomal cytochrome P-450 dependent enzyme activity [169]. This hypothesis came from some experimental evidence, in which it was demonstrated that carbamazepine metabolites can make a covalent bond to the hepatic microsomes, inducing a toxic reaction [170]. However, the data obtained from a cross-sectional study including 130 patients suffering from idiopathic epilepsy reveals that only the VPA seems to alter significantly the serum lipid levels, whereas other drugs such as carbamazepine and lamotrigine show no effects [171].

\subsection{Glucocorticoids}

Synthetic glucocorticoids (GCs), such as dexamethasone, betamethasone, prednisolone and triamcinolone, control various physiological functions including development, homeostasis, metabolism, cognition and inflammation [172] and are generally employed for their anti-inflammatory properties at high doses and prolonged periods. Glucocorticoids are among the most widely prescribed medicaments, so much so that the global income that revolves around the sale of glucocorticoids amounts to more than 10 billion dollars/year [173]. In particular, glucocorticoids are used in the treatment of many clinical manifestations such as asthma, allergy, septic shock, rheumatoid arthritis, inflammatory bowel disease, and multiple sclerosis [174]. Unfortunately, the prolonged use of GCs can produce many side effects, including insulin resistance, hepatic lipid deposition and steatosis [175]. It is well known that one of the most immediate effects of GC administration is an increased appetite, which may result in weight gain. This initial condition is followed by hepatic fatty acid deposition, dyslipidemia, insulin resistance, muscle wasting, hypertension, skin and skeletal fragility and psychological disorders. All these abnormalities are commonly observed in patients suffering from Cushing's syndrome, who display elevated cortisol levels $[176,177]$. Studies have been conducted to shed light on the mechanisms involved in the onset of these symptoms. For example, it has been demonstrated that GC levels above the physiological threshold induce hyperphagia and obesity, probably due to a reduced sensitivity to leptin [178-180]. In fact, it has been reported both in Huh7 cells and in rats, that the leptin bound to its receptor OBRb initiates a tyrosine cascade phosphorylation after JAK/STAT signaling activation [181]; this pathway is blocked by GCs [179]. Moreover, after GC prolonged administration, insulin resistance and elevated glucose occur, leading to ChREBP and SREBP-1c increase. These events promote the GC-mediated increase in the de novo lipogenesis, upregulating genes such as ACC and FAS [182]. SREPB-1c is also involved in the inhibition of PPAR $\gamma$ coactivator $1 \alpha$ (PGC-1 $\alpha)$, which activates phosphoenolpyruvate carboxykinase (PEPCK), a rate-limiting enzyme that promotes gluconeogenesis [183]. At the same time, the increased glucose disposal favors the synergistic effect of ChREBP and SREBP-1c [184]. Lastly, recent studies reported that, after GC administration, an upregulation of mitogen-activated protein kinase phosphatase-3 (MKP3) plays a critical role in GC-induced hepatic de novo lipid deposition. In fact, mouse hepatoma cells (Hepa1-6) treated with $2.5 \mu \mathrm{M}$ dexamethasone for $2 \mathrm{~h}$, displayed increased expression of MKP3 via the forkhead box protein $\mathrm{O} 1$ (FOXO1) and the same result was obtained in lean mice treated with $15 \mathrm{mg} / \mathrm{kg}$ dexamethasone for 28 days. The role of MKP3 was also confirmed using MKP3 knockout (MKP-/-) mice versus wild type (WT) mice. Dexamethasone injection caused a significant increase in the bodyweight of WT mice after five weeks of injection, when compared with vehicle-treated mice. On the contrary, no weight gain was observed in MKP3 - / - mice. In addition, dexamethasone-induced triglyceride hepatic accumulation was totally abolished in MKP3-/- mice, when compared with WT mice. It was also shown that, in MKP3- / - and not in WT mice, dexamethasone injection did not increase the expression of lipid synthesis genes, such as PPAR $\gamma$, FAS, SCD1 and ACC [185].

Another mechanism by which GCs cause NAFLD is through the increased uptake of free fatty acid in the liver by the upregulation of CD36 fatty acid transporter [175]. In fact, studies by D'souza and colleagues demonstrated that the subcutaneous implantation of four $100 \mathrm{mg}$-corticosterone pellets or placebo in rats for 16 days induced a CD36 expression 
increase when the pharmacological treatment was associated with both a high-fat diet and a standard diet [186].

Moreover, GCs administration causes hepatic lipid accumulation by causing a decreased secretion of lipids in form of very low density lipoproteins (VLDL). In particular, both in vitro and in vivo experiments demonstrated that dexamethasone administration affects the stability of mRNA of hepatic triacylglycerol hydrolase (TGH), the lipase that hydrolyses triacylglycerol (TAG) before its re-esterification to form VLDL. On the other hand, dexamethasone upregulates the expression and activity of diacylglycerol acyltransferases 1 and 2, favoring the de novo TAG synthesis [187]. Thus, by increasing the de novo lipogenesis and decreasing the utilization of stored TAG for VLDL synthesis, GC administration produces further hepatic lipid droplet formation and steatosis onset and progression.

An additional mechanism contributing to GC-induced hepatic steatosis is the decreased beta-oxidation rate, caused by a decreased activity of the PPAR $\alpha$-FGF21 axis, as seen in high-fat-fed mice overexpressing glucocorticoid receptor $\beta(G R \beta)$ at the hepatic level [175]. Moreover, at the same time, GR $\beta$ overexpression is involved in inflammatory process activation by the secretion of TNF- $\alpha$ and inducible nitric oxide synthase (iNOS) upregulation. These events lead to macrophage infiltration in the liver and the further increase in lipid deposition and NAFLD progression [188] (Figure 4).

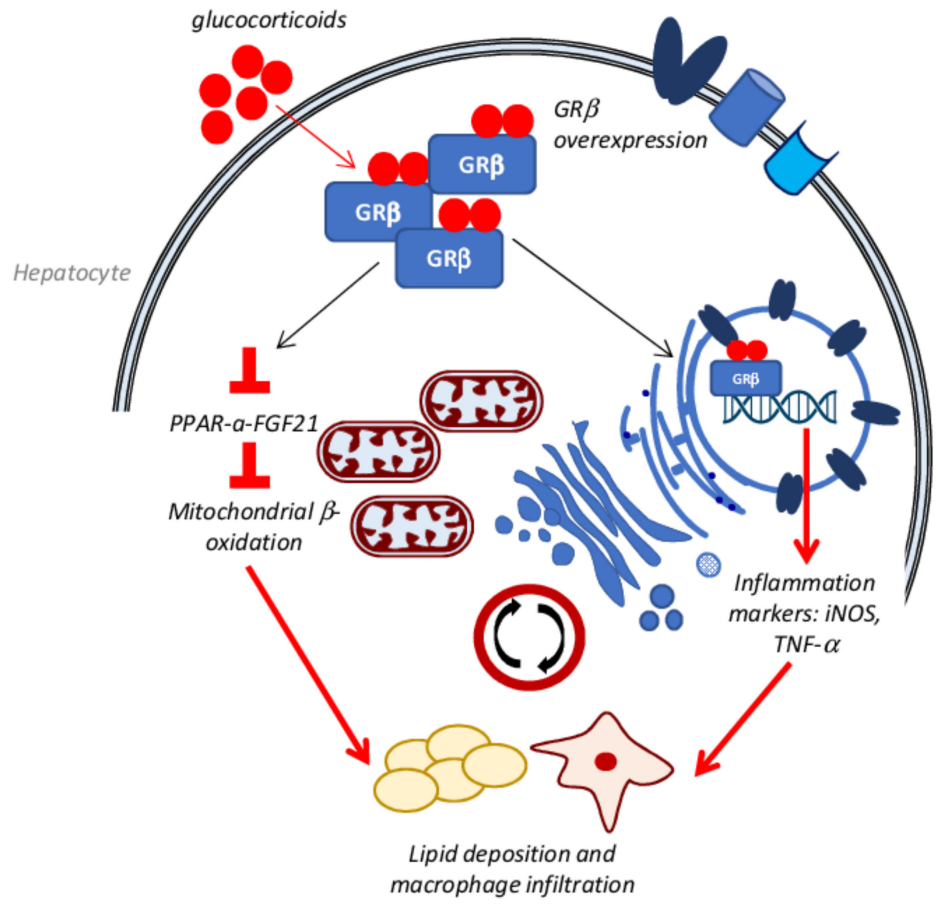

Figure 4. Schematic representation of glucocorticoid receptor $\beta(G R \beta)$ contribution in hepatic lipid deposition. GR $\beta$ overexpression induces both the inhibition of the PPAR $\alpha$-FGF21 signal pathway, decreasing $\beta$-oxidation of fatty acid, and at the same time is involved in inflammatory process establishment by the secretion of TNF- $\alpha$ and upregulation of iNOS protein expression. This condition leads to further lipid deposition and macrophage hepatic infiltration.

The transcriptional coactivator of the glucocorticoid receptor MED1/PPARBP [189] is also necessary to induce steatosis. In fact, a conditional gene disruption of MED1 in mouse liver resulted in the loss of dexamethasone ability to induce hepatic steatosis [189].

Lastly, it has been recently demonstrated that angiopoietin-like 4 (ANGPTL4, fastinginduced adipose factor), a primary downstream gene of GC receptor signaling pathway in both hepatocytes and adipocytes, is strictly linked with the GC-induced hepatic steatosis 
and hypertriglyceridemia. In Angptl4 knockout mice (Angptl4-/ -), despite the administration of dexamethasone, the rate of hepatic steatosis and hypertriglyceridemia were significantly decreased [190].

\subsection{Nonsteroidal Anti-Inflammatory Drugs (NSAIDs)}

Nonsteroidal anti-inflammatory drugs (NSAIDs) are among the most prescribed medications in the world for their analgesic, anti-inflammatory and antipyretic properties [191]. It is estimated that more than 30 million people consume NSAIDs every day, and this number will probably continue to increase over time. Despite the efficacy and the spread of NSAIDs, they cause a plethora of side effects [192]. In about $60-70 \%$ of patients, long-term administration of NSAIDs is related to the development of mucosal damage [193-195], as alteration of intestinal permeability, inflammation, erosion of gastrointestinal epithelia, protein loss, anemia, bleeding [196,197]. Many NSAIDs are listed in the category of drugs inducing steatosis. Contradictory data were published on aspirin or salicylic acid. In some studies, aspirin was found to cause liver damage through the induction of mitochondrial dysfunction, which leads to metabolic abnormalities and microsteatosis as part of the clinical picture of Reye's syndrome. Reye's syndrome is an acute encephalopathy characterized by liver damage, which is one of the aspirin side effects in children. For this reason aspirin is replaced by ibuprofen or paracetamol in pediatric patients [198]. Moreover, experimental studies conducted in isolated rat hepatocytes suggest that salicylic acid administration caused hepatic cell death mediated by mitochondrial dysfunction after dose-dependent ATP depletion and lipid peroxidation [199]. On the other hand, in rats fed with a choline-deficient, L-amino acid-defined (CDAA) diet to induce NASH, 150 $\mathrm{mg} / \mathrm{kg}$ /day of aspirin significantly reduces liver steatosis, inflammation and fibrosis [200]. Similarly, Ibrahim and colleagues demonstrated that the administration of NO-aspirin in cholesterol-diet fed rats significantly decreases hepatic triglycerides, malondialdehyde and nitric oxide, by reducing inducible nitric oxide synthase (iNOS) and cyclooxygenase-2 (COX-2) [201]. Different possible molecular mechanisms have been proposed to explain the potential protective role of salicylic acid in NAFLD. It is well known that aspirin acts on various targets, which can all play a beneficial role in NAFLD [202]. Firstly, aspirin induces the expression of endothelial nitric oxide synthase (eNOS) and vascular endothelial growth factor (VEGF), resulting in an antioxidant response [203]; then, the aspirin-mediated inhibition of iNOS and TNF- $\alpha$ decreases inflammation and fibrosis [204]. Aspirin also reduces the expression of platelet-derived growth factor (PDGF)-C, through the inhibition of TGF $\beta$-regulate profibrotic pathway [205]. Lastly, aspirin inhibits the activation of the mitogen-activated protein kinase (MAPK) pathway induced by PDGF, so promoting a reduction in Jun N-terminal kinase (JNK) activity, which leads to the initiation of the insulin signaling pathway, ameliorating insulin resistance [206]. Data about aspirin-induced protection from NAFLD were also obtained in patients; in fact, it has been demonstrated in a cross-sectional study that the use of aspirin is associated with a lower prevalence of NAFLD in general US population, in particular in men and elderly patients [202]. More recently, Simon et al. demonstrated in a prospective cohort study of 361 adults suffering from NAFLD, that daily use of aspirin reduces the histologic features of NAFLD and NASH and the risk of progression to advanced fibrosis [207]. Thus, further investigations are needed to completely clarify the role of aspirin in NAFLD development.

Acetaminophen (APAP) is the most used analgesic and antipyretic agent in the world since its first introduction in clinical practice in 1955. It is considered a safe drug, but it may cause fatal acute liver failure when the dose exceeds $4 \mathrm{~g} /$ day. Several studies reported that its administration is more dangerous in patients already suffering from NAFLD, NASH or obesity. APAP-induced liver damage is related to the CYP3A4 and CYP2E1-mediated generation of its metabolite N-acetyl-p-benzoquinone imine (NAPQI), which is detoxified by glutathione (GSH) [208]. In already compromised hepatocytes, as they are in NAFLD or NASH, GSH stores are poor because of the increased activity of CYP450, in particular CYP2E1, which is post-transductionally upregulated by insulin. In 
fact, in primary hepatocytes isolated from high-fat diet-fed rats, the administration of APAP causes an excess of NAPQI production and the subsequent generation of ROS and adducts in proteins and other biomolecules, leading to mitochondrial damage and further depletion of GSH stores [209]. Moreover, in mice, after APAP intoxication, an accumulation of acylcarnitine in serum and liver occurs $[210,211]$ correlated with a concomitant intrahepatic lipid deposition and an inhibition of mitochondrial long-chain fatty acid oxidation [212]. This mechanism could explain the APAP-induced microvesicular steatosis onset in rodents. It has been suggested, in fact, that NAPQI probably binds in a covalent way to one of the enzymes involved in long-chain fatty acid oxidation [48] or, alternatively, it can interact with MRC, leading to an accumulation of long-chain acylcarnitines [213]. Lastly, studies by Li et al. demonstrated that APAP intoxication significantly reduces hepatic PPAR $\alpha$ expression via the stabilization of hypoxia inducible factor- $1 \alpha(\mathrm{HIF}-1 \alpha)$, leading to $\mathrm{mtFAO}$ impairment [214,215].

A similar mechanism of action was attributed also to pirprofen and ibuprofen [216,217]. Both drugs are 2-arylpropionates with an asymmetric carbon that produces two enantiomers, the $\mathrm{S}^{+}$and $\mathrm{R}^{-}$forms. Except for naproxen, this category of anti-inflammatory drugs is commercialized as racemate mixtures [217] (Figure 5).

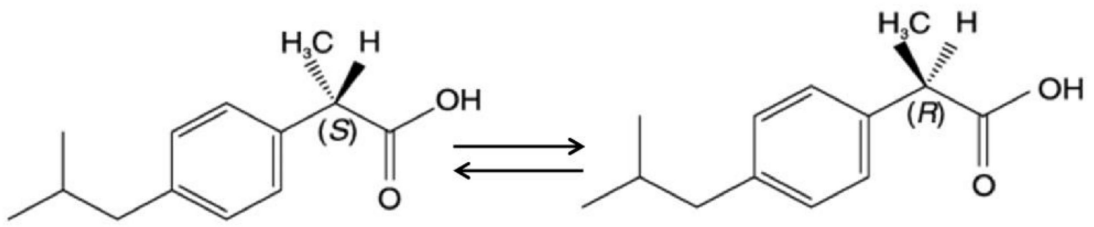

(S)-ibuprofen

(R)-ibuprofen

Figure 5. Ibuprofen $\mathrm{S}^{+}$and $\mathrm{R}^{-}$structure. The majority of NSAIDs are commercialized as the racemate mixture.

It was believed for a long time that only the $\mathrm{S}^{+}$enantiomer of ibuprofen had antiinflammatory properties [218], while the $\mathrm{R}^{-}$enantiomer formed an acyl coenzyme A derivative that was incorporated into lipids $[219,220]$ and inhibited mitochondrial oxidation of natural coenzyme A. However, it has been proven that both enantiomers can inhibit mtFAO in vitro and in vivo, and that the $\mathrm{R}^{-}$enantiomer can stereoselectively bind to coenzyme $\mathrm{A}$ in vitro, when CoA is at low concentration, so inhibiting long chain fatty acids mitochondrial uptake and beta oxidation [217]. It has been demonstrated that pirprofen also induces microvesicular steatosis through mtFAO inhibition. In fact, $2 \mathrm{mM}$ pirprofen administration to rat mitochondria decreased by $50 \%$ the formation of $\left[{ }^{14} \mathrm{C}\right]$ acid-soluble beta-oxidation products and reduced by $70 \%$ the formation of $\left[{ }^{14} \mathrm{C} \mathrm{CO}_{2}\right.$ when hepatic mitochondria were incubated with $\left[{ }^{14} \mathrm{C}\right]$ palmitic acid, ATP, carnitine and coenzyme A. The same authors obtained similar data after $2 \mathrm{mmol} / \mathrm{kg}$ pirprofen administration in vivo, observing also a doubled deposition of triglycerides in the liver tissue [216]. Lastly, a recent study from $\mathrm{Lu}$ and colleagues revealed that ibuprofen inhibits the transcriptional activity of farnesoid $X$ receptor (FXR) in HepG2 cells [221]. It is known that FXR is one of the most important regulators of hepatic triglycerides, so its inhibition by ibuprofen could be related to the onset of steatosis after ibuprofen administration.

Diclofenac, a phenylacetic acid, and naproxen, a propionic acid, have been reported to induce microvacuolar steatosis through the inhibition of mtFAO. In particular, diclofenac inhibits the glutamate/malate-driven respiration on mitochondria isolated from ob/ob mice [222], while naproxen has been proposed to inhibit $\beta$-oxidation of short- and mediumchain fatty acids [223].

Few data have been published in the literature about ketoprofen-induced NAFLD; in a case report by Famularo and colleagues, the administration of this drug was associated with fatty acid deposition in the hepatic parenchyma, accompanied by cholestasis and transaminase release. This clinical picture suggests that ketoprofen may induce the 
inhibition of mitochondrial function with consequent accumulation of lipids and ROS, lipid peroxidation, hepatocyte apoptosis and necrosis and dysregulation of bile secretory machinery [224].

\subsection{Nucleoside Reverse Transcriptase Inhibitors (NRTIs)}

Nucleoside reverse transcriptase inhibitors (NRTIs) include many drugs, such as zidovudine, didanosine, stavudine, lamivudine, zalcitabine, abacavir and tenofovir used for the treatment of virus infections from the human immunodeficiency virus (HIV) or the Hepatitis B virus (HBV). Some NRTIs can induce many side effects including hepatic steatosis [225]. In particular, two cross-sectional studies conducted in patients affected by HIV demonstrated that the prevalence of NAFLD, in patients treated with NRTIs, ranges from $31 \%$ to $37 \%$ [226,227]. NRTIs are $2^{\prime}, 3^{\prime}$-dideoxynucleosides without the hydroxyl group in $3^{\prime}$ position of the sugar ring; once incorporated into the viral DNA chain, they inhibit its elongation, blocking the reverse transcriptase enzymes [228]. However, they can act also as substrates for human DNA polymerases and, in particular, they can inhibit the human DNA polymerase $\gamma$, the only one able to replicate the mitochondrial DNA $[229,230]$, leading to mitochondrial dysfunction and subsequent hepatotoxicity, hepatic steatosis and lactic acidosis. NRTIs mostly involved in this kind of mechanism are zidovudine, stavudine and didanosine [231].

Zidovudine (3-azido-3'-deoxythymidine or AZT), was the first drug approved by US Food and Drug Administration for the treatment of AIDS and it is still the most employed compound to treat HIV infected patients [232]. However, many patients infected by HIV and treated with AZT develop lethal liver abnormalities, such as lipid dysregulation and accumulation, steatohepatitis and acidosis [14-17]. Studies conducted in mice demonstrated that the mechanism of AZT-induced fatty acid accumulation in the hepatic parenchyma is due to AZT-induced oxidative and endoplasmic reticulum stress. In fact, C57BL/6J female mice administered intraperitoneally with $400 \mathrm{mg} / \mathrm{Kg} /$ day AZT for 10 days, displayed a significant increase in hepatic triglyceride levels and inflammation markers, such as lipid peroxidation and protein modification, as well as in ER stress markers, such as the molecular chaperone glucose-regulated protein 78 (GRP78) and its downstream targets, including protein kinase-like endoplasmic reticulum kinase (PERK) and the eukaryotic translation initiation factor-2 $\alpha$ (eIF2 $\alpha)$. Moreover, these mice displayed increased levels of nuclear SREPB-1c, while PPAR $\alpha$, phospho-AMP kinase and 3-keto-acyl-CoA thiolase were significantly decreased, suggesting that these alterations in fatty acid metabolism could be part of the mechanism by which AZT induces steatosis [232].

Another mechanism by which NRTIs can induce steatosis is the inhibition of autophagy. Stankov and colleagues demonstrated, using HepG2, Huh7 and primary human hepatocytes, that both AZT and stavudine inhibit constitutive and induced autophagy in a dose- and time-dependent manner. This occurrence causes mitochondrial dysfunction, ROS accumulation and augmented apoptosis, accompanied by increased lipid deposition within the cells, contributing to NAFLD in HIV-infected patients [233]. Finally, it has been reported that, in a clinical picture of $\mathrm{HIV} / \mathrm{HCV}$ coinfection, the combined therapy with didanosine and ribavirin caused mitochondrial toxicity and consequent lipid deposition, due to reduced didanosine phosphorylation and its cytosolic accumulation [234]. Didanosine itself also leads to a dose-dependent inhibition of oxygen consumption and complex I and III activity, causing mitotoxicity and reduced ATP production. In fact, Sun et al. demonstrated in vitro that didanosine inhibited mitochondrial thymidine kinase 2 (TK2) and deoxyguanosine kinase (dGK), which are essential for mitochondrial function since they are involved in the initial rate-limiting phosphorylation of deoxynucleosides. Their inhibition led to mtDNA depletion, demonstrated by a $10 \%$ reduction in cytochrome c oxidase subunit II (COX II) protein synthesis, which is encoded by mitochondrial DNA [235]. 


\subsection{Zonal Heterogeneity in Drug-Induced Lipid Accumulation}

A difference in glucose and fatty acid metabolism has been observed in hepatocytes with respect to proximity to the portal triad, probably due to the existing gradient of nutrients and oxygen. While periportal hepatocytes are more involved in gluconeogenesis and $\beta$-oxidation of fatty acids, glycolysis and lipogenesis occur at a higher rate in centrilobular hepatocytes [236]. Additionally, lipids are distributed differentially within the liver lobule. One of the distinctive features of steatosis in adult NAFLD, in contrast to most pediatric NAFLD cases, is its predilection to start in zone 3 (centrilobular region); adult NASH presents steatosis in the form of ballooning, also typically localized in zone 3 [237]. An intralobular heterogeneous distribution of lipids has been observed for certain drugs. In particular, steatohepatitis has been observed in patients treated with agents such as methotrexate, amiodarone, perhexiline and tamoxifen. In these patients, NASH-like lesions were found, with centrilobular ballooning and perisinusoidal fibrosis [238,239]. In a study conducted on patients treated with methotrexate for rheumatoid arthritis, in $4.6 \%$ of patients with fatty liver, liver biopsy showed that the majority of them had a NASH-like pattern, with steatosis, centrilobular ballooning degeneration, and centrilobular perisinusoidal fibrosis [240]. However, it should be noted that the risk of significant fatty liver disease related to tamoxifen or methotrexate increases if the patient is already obese or diabetic, suggesting a synergistic effect [239]; so, the observed zonation in patients taking these drugs may be a consequence of the preexisting disease. Drug-induced microvesicular steatosis is restricted to a limited list of agents that primarily induce mitochondrial damage, including 2-arylproprionic acids, aspirin, tetracycline, valproic acid, fialuridine, antiretroviral drugs; for this kind of drug, heterogeneity in lipid deposition has not been reported [44].

\section{Conclusions}

Non-alcoholic fatty liver disease (NAFLD) and non-alcoholic steatohepatitis (NASH) today represent two of the major health challenges facing Western countries. A significant percentage of NAFLD and NASH is induced by the administration of drugs (DIFLD and DISH) for the treatment of extremely widespread pathologies such as hypertension and cardiovascular disorders, bacterial and viral infections, or tumors. A detailed understanding of the molecular mechanisms involved in the onset of NAFLD and NASH following the administration of specific drugs is certainly useful to minimize adverse effects in susceptible patients and to recommend alternative treatment solutions that reduce hepatotoxicity without interrupting the therapy.

Author Contributions: Conceptualization, L.G.D.P., A.F. and M.C.; writing-original draft preparation, L.G.D.P.; writing-review and editing, L.G.D.P.; and A.F.; visualization, M.C. and C.B.; supervision, A.F. and M.V. All authors have read and agreed to the published version of the manuscript.

Funding: This research received no external funding.

Acknowledgments: The authors thank Micaela Ascoli and Nicoletta Breda for administrative and technical support.

Conflicts of Interest: The authors declare no conflict of interest.

\section{Abbreviations}

$\begin{array}{ll}\text { ACC } & \text { Acetyl CoA carboxylase } \\ \text { ACE } & \text { Angiotensin-converting enzyme } \\ \text { ACLY } & \text { ATP-citrate synthase } \\ \text { ACOX1 } & \text { Acyl-CoA oxidase } 1 \\ \text { AIDS } & \text { Acquired immune deficiency syndrome } \\ \text { ALP } & \text { Alkaline phosphatase } \\ \text { ALT } & \text { Alanine aminotransferase }\end{array}$




\begin{tabular}{|c|c|}
\hline ANGPTL4 & Angiopoietin-like 4 \\
\hline Ang II & Angiontensin II \\
\hline APAP & Acetaminophen \\
\hline ApoB100 & Apolipoprotein B100 \\
\hline AST & Aspartate transaminase \\
\hline ATF4 & Activating transcription factor 4 \\
\hline AZT & Zidovudine (3-azido-3'-deoxythymidine) \\
\hline Bix & 1-(3,4-dihydroxyphenyl)-2-thiocyanate-ethanone \\
\hline $\mathrm{BSO}$ & L-buthionine-(S,R)-sulfoximine \\
\hline CASH & Chemotherapy-associated steatohepatitis \\
\hline $\mathrm{CCl}_{4}$ & Carbon tetrachloride \\
\hline CD36 & Cluster of differentiation 36 \\
\hline CDAA & L-amino acid-defined \\
\hline CHOP & CCAAT-enhancer-binding protein homologous protein \\
\hline ChREBP & Carbohydrate regulatory element-binding protein \\
\hline Cidea & Lipid droplet proteins cell death activator \\
\hline Cidec & Cell death inducing DFFA like effector C \\
\hline COX II & Cytochrome c oxidase subunit II \\
\hline COX-2 & Cyclooxygenase-2 \\
\hline CPT1 & carnitine palmitoyltransferase 1 \\
\hline CYP2E1 & Cytochrome P450 2E1 \\
\hline DEX & Dexamethasone \\
\hline DGAT2 & Diacylglycerol acyltransferase 2 \\
\hline dGK & Deoxyguanosine kinase \\
\hline DIFLD & Drug-induced fatty liver disease \\
\hline DIHS & Drug-induced hepatic steatosis \\
\hline DILI & Drug-induced liver injury \\
\hline DISH & Drug-induced steatohepatitis \\
\hline DISH & Drug-induced steatohepatitis \\
\hline DNL & De novo lipogenesis \\
\hline DPD & Dihydropyrimidine dehydrogenase \\
\hline $\mathrm{eIF} 2 \alpha$ & Eukaryotic translation initiation factor- $2 \alpha$ \\
\hline ELP & Enalapril \\
\hline eNOS & Endothelial nitric oxide synthase \\
\hline ER & Endoplasmic reticulum \\
\hline $\mathrm{FAO}$ & Fatty acid oxidation \\
\hline FAS & Fatty acid synthase \\
\hline FATP & Fatty acid transport protein \\
\hline FOXO1 & Forkhead box protein $\mathrm{O} 1$ \\
\hline 5-FU & 5-fluorouracil \\
\hline FXR & Farnesoid $X$ receptor \\
\hline GC & Glucocorticoid \\
\hline GR & Glucocorticoid receptor \\
\hline GRP78 & Glucose-regulated protein 78 \\
\hline GSH & Reduced glutathione \\
\hline HAART & Highly active antiretroviral therapy \\
\hline $\mathrm{HADH} \beta$ & Beta-3-hydroxyacyl CoA dehydrogenase \\
\hline $\mathrm{HCV}$ & Hepatitis $C$ virus \\
\hline Hepa1-6 & Mouse hepatoma cells \\
\hline HSC & Hepatic stellate cells \\
\hline $\mathrm{HIF}-1 \alpha$ & Hypoxia-inducible factor 1 alpha \\
\hline HFHC & High-fat, high calorie, high-fructose \\
\hline HIV & Human immunodeficiency virus \\
\hline
\end{tabular}




\begin{tabular}{|c|c|}
\hline HMOX1 & Heme oxygenase 1 \\
\hline Sabi $\Delta$ Hep & Inducible hepatocyte specific SAB deletion \\
\hline iNOS & Inducible nitric oxide synthase \\
\hline JNK & c-Jun N-terminal kinases \\
\hline LPO & Lipid hydroperoxides \\
\hline MAFLD & Metabolic associated fatty liver disease \\
\hline MAPK & Mitogen-activated protein kinase \\
\hline MCD & Methionine and choline deficient \\
\hline MCR & Mitochondrial respiratory chain \\
\hline MKP3 & Mitogen-activated protein kinase phosphatase-3 \\
\hline mTOR & Mammalian target of rapamycin \\
\hline MTP & Microsomal triglyceride transfer protein \\
\hline MTTP & Microsomal triglyceride transfer protein \\
\hline MTX & Methotrexate \\
\hline NAFLD & Non-alcoholic fatty liver disease \\
\hline NAPQI & N-acetyl-p-bemzoquinone imine \\
\hline NASH & Non-alcoholic steatohepatitis \\
\hline NLRP3 & Nod-like receptor protein 3 \\
\hline NRTIs & Nucleoside reverse transcriptase inhibitors \\
\hline NSAIDs & Nonsteroidal anti-inflammatory agents \\
\hline OCA & Obeticholic acid \\
\hline OXPHOS & Oxidative phosphorylation \\
\hline PDGF-C & Platelet-derived growth factor-C \\
\hline PEPCK & Phosphoenolpyruvate carboxykinase \\
\hline PERK & Protein kinase-like endoplasmic reticulum kinase \\
\hline PGC-1 $\alpha$ & PPAR $\gamma$ coactivator $1 \alpha$ \\
\hline PPAR & Peroxisome roliferator-activated receptor \\
\hline RAAS & renin-angiotensin-aldosterone system \\
\hline ROS & Reactive oxygen species \\
\hline SAB & SH3BP5 protein \\
\hline (GalNAc-Sab-ASO) & SAB N-acetylgalactosamine antisense oligonucleotid \\
\hline SREBP-1c & Sterol regulatory element-binding protein $1 C$ \\
\hline sXBP1 & spliced X-box binding protein 1 \\
\hline TAG & Triacylglycerol \\
\hline TGF $\beta 1$ & Transforming growth factor- $\beta 1$ \\
\hline TGH & Triacylglycerol hydrolase \\
\hline TK2 & Thymidine kinase 2 \\
\hline $\mathrm{TNF}-\alpha$ & Tumor necrosis factor alpha \\
\hline TXNIP & Thioredoxin-interacting protein \\
\hline VEGF & Vascular endothelial growth factor \\
\hline VLDL & Very low density lipoprotein \\
\hline VPA & Valproic acid \\
\hline WT & Wild type \\
\hline$\alpha-S M A$ & $\alpha$-smooth muscle actin \\
\hline$\gamma-\mathrm{GT}$ & Gamma-glutamyltransferase \\
\hline
\end{tabular}

\section{References}

1. Palladini, G.; Di Pasqua, L.G.; Berardo, C.; Siciliano, V.; Richelmi, P.; Mannucci, B.; Croce, A.C.; Rizzo, V.; Perlini, S.; Vairetti, M.; et al. Fatty acid desaturase involvement in non-alcoholic fatty liver disease rat models: Oxidative stress versus metalloproteinases. Nutrients 2019, 11, 799. [CrossRef] [PubMed]

2. Berardo, C.; Di Pasqua, L.G.; Cagna, M.; Richelmi, P.; Vairetti, M.; Ferrigno, A. Nonalcoholic Fatty Liver Disease and NonAlcoholic Steatohepatitis: Current Issues and Future Perspectives in Preclinical and Clinical Research. Int. J. Mol. Sci. 2020, 21, 9646. [CrossRef] [PubMed]

3. Stefan, N.; Häring, H.U.; Cusi, K. Non-alcoholic fatty liver disease: Causes, diagnosis, cardiometabolic consequences, and treatment strategies. Lancet Diabetes Endocrinol. 2019, 7, 313-324. [CrossRef] 
4. Liu, D.J.; Peloso, G.M.; Yu, H.; Butterworth, A.S.; Wang, X.; Mahajan, A.; Saleheen, D.; Emdin, C.; Alam, D.; Alves, A.C.; et al. Exome-wide association study of plasma lipids in $>300,000$ individuals. Nat. Genet. 2017, 49, 1758-1766. [CrossRef]

5. Musso, G.; Cipolla, U.; Cassader, M.; Pinach, S.; Saba, F.; De Michieli, F.; Paschetta, E.; Bongiovanni, D.; Framarin, L.; Leone, N.; et al. TM6SF2 rs58542926 variant affects postprandial lipoprotein metabolism and glucose homeostasis in NAFLD. J. Lipid Res. 2017, 58, 1221-1229. [CrossRef]

6. Younossi, Z.M.; Rinella, M.E.; Sanyal, A.J.; Harrison, S.A.; Brunt, E.M.; Goodman, Z.; Cohen, D.E.; Loomba, R. From NAFLD to MAFLD: Implications of a Premature Change in Terminology. Hepatology 2021, 73, 1194-1198. [CrossRef]

7. Younossi, Z.M.; Koenig, A.B.; Abdelatif, D.; Fazel, Y.; Henry, L.; Wymer, M. Global epidemiology of nonalcoholic fatty liver disease-Meta-analytic assessment of prevalence, incidence, and outcomes. Hepatology 2016, 64, 73-84. [CrossRef]

8. Jinjuvadia, R.; Antaki, F.; Lohia, P.; Liangpunsakul, S. The Association between Nonalcoholic Fatty Liver Disease and Metabolic Abnormalities in United States Population. J. Clin. Gastroenterol. 2017, 51, 160. [CrossRef]

9. Younossi, Z.M.; Golabi, P.; de Avila, L.; Paik, J.M.; Srishord, M.; Fukui, N.; Qiu, Y.; Burns, L.; Afendy, A.; Nader, F. The global epidemiology of NAFLD and NASH in patients with type 2 diabetes: A systematic review and meta-analysis. J. Hepatol. 2019, 71, 793-801. [CrossRef]

10. Buzzetti, E.; Pinzani, M.; Tsochatzis, E.A. The multiple-hit pathogenesis of non-alcoholic fatty liver disease (NAFLD). Metabolism 2016, 65, 1038-1048. [CrossRef]

11. Ferrigno, A.; Berardo, C.; Di Pasqua, L.G.; Cagna, M.; Siciliano, V.; Richelmi, P.; Vairetti, M. The selective blockade of metabotropic glutamate receptor- 5 attenuates fat accumulation in an in vitro model of benign steatosis. Eur. J. Histochem. 2020, $64,3175$.

12. Rabinowich, L.; Shibolet, O. Drug induced steatohepatitis: An uncommon culprit of a common disease. Biomed Res. Int. 2015, 2015, 168905. [CrossRef]

13. Amacher, D.E.; Chalasani, N. Drug-induced hepatic steatosis. Semin. Liver Dis. 2014, 34, 205-214.

14. Freiman, J.P.; Helfert, K.E.; Hamrell, M.R.; Stein, D.S. Hepatomegaly with severe steatosis in HIV-seropositive patients. AIDS 1993, 7, 379-385. [CrossRef] [PubMed]

15. Olano, J.P.; Borucki, M.J.; Wen, J.W.; Haque, A.K. Massive hepatic steatosis and lactic acidosis in a patient with AIDS who was receiving zidovudine. Clin. Infect. Dis. 1995, 21, 973-976. [CrossRef] [PubMed]

16. Chariot, P.; Drogou, I.; De Lacroix-Szmania, I.; Eliezer-Vanerot, M.C.; Chazaud, B.; Lombès, A.; Schaeffer, A.; Zafrani, E.S. Zidovudine-induced mitochondrial disorder with massive liver steatosis, myopathy, lactic acidosis, and mitochondrial DNA depletion. J. Hepatol. 1999, 30, 156-160. [CrossRef]

17. Acosta, B.S.; Grimsley, E.W. Zidovudine-associated type B lactic acidosis and hepatic steatosis in an HIV-infected patient. South. Med. J. 1999, 92, 421-423. [CrossRef] [PubMed]

18. Schumacher, J.D.; Guo, G.L. Mechanistic review of drug-induced steatohepatitis. Toxicol. Appl. Pharmacol. 2015, 289, 40-47. [CrossRef]

19. Esler, W.P.; Bence, K.K. Metabolic Targets in Nonalcoholic Fatty Liver Disease. Cell. Mol. Gastroenterol. Hepatol. 2019, 8, 247-267. [CrossRef]

20. Ipsen, D.H.; Lykkesfeldt, J.; Tveden-Nyborg, P. Molecular mechanisms of hepatic lipid accumulation in non-alcoholic fatty liver disease. Cell. Mol. Life Sci. 2018, 75, 3313-3327. [CrossRef]

21. Falcon, A.; Doege, H.; Fluitt, A.; Tsang, B.; Watson, N.; Kay, M.A.; Stahl, A. FATP2 is a hepatic fatty acid transporter and peroxisomal very long-chain acyl-CoA synthetase. Am. J. Physiol.-Endocrinol. Metab. 2010, 299, E384-E393. [CrossRef] [PubMed]

22. Doege, H.; Grimm, D.; Falcon, A.; Tsang, B.; Storm, T.A.; Xu, H.; Ortegon, A.M.; Kazantzis, M.; Kay, M.A.; Stahl, A. Silencing of Hepatic Fatty Acid Transporter Protein 5 in Vivo Reverses Diet-induced Non-alcoholic Fatty Liver Disease and Improves Hyperglycemia. J. Biol. Chem. 2008, 283, 22186-22192. [CrossRef] [PubMed]

23. Wilson, C.G.; Tran, J.L.; Erion, D.M.; Vera, N.B.; Febbraio, M.; Weiss, E.J. Hepatocyte-specific disruption of CD36 attenuates fatty liver and improves insulin sensitivity in HFD-fed mice. Endocrinology 2016, 157, 570-585. [CrossRef]

24. Miquilena-Colina, M.E.; Lima-Cabello, E.; Sánchez-Campos, S.; García-Mediavilla, M.V.; Fernández-Bermejo, M.; LozanoRodríguez, T.; Vargas-Castrillón, J.; Xabier Buqué, B.O.; Aspichueta, P.; González-Gallego, J.; et al. Hepatic fatty acid translocase CD36 upregulation is associated with insulin resistance, hyperinsulinaemia and increased steatosis in non-alcoholic steatohepatitis and chronic hepatitis C. Gut 2011, 60, 1394-1402. [CrossRef] [PubMed]

25. Diraison, F.; Moulin, P.H.; Beylot, M. Contribution of hepatic de novo lipogenesis and reesterification of plasma non esterified fatty acids to plasma triglyceride synthesis during non-alcoholic fatty liver disease. Diabetes Metab. 2003, 29, 478-485. [CrossRef]

26. Donnelly, K.L.; Smith, C.I.; Schwarzenberg, S.J.; Jessurun, J.; Boldt, M.D.; Parks, E.J. Sources of fatty acids stored in liver and secreted via lipoproteins in patients with nonalcoholic fatty liver disease. J. Clin. Investig. 2005, 115, 1343-1351. [CrossRef] [PubMed]

27. Koo, S.H. Nonalcoholic fatty liver disease: Molecular mechanisms for the hepatic steatosis. Clin. Mol. Hepatol. 2013, 19, 210-215. [CrossRef]

28. Nassir, F.; Ibdah, J.A. Role of mitochondria in nonalcoholic fatty liver disease. Int. J. Mol. Sci. 2015, 15, 8713-8742. [CrossRef]

29. Gao, Q.; Jia, Y.; Yang, G.; Zhang, X.; Boddu, P.C.; Petersen, B.; Narsingam, S.; Zhu, Y.J.; Thimmapaya, B.; Kanwar, Y.S.; et al. PPAR $\alpha$-deficient ob/ob obese mice become more obese and manifest severe hepatic steatosis due to decreased fatty acid oxidation. Am. J. Pathol. 2015, 185, 1396-1408. [CrossRef] 
30. Francque, S.; Verrijken, A.; Caron, S.; Prawitt, J.; Paumelle, R.; Derudas, B.; Lefebvre, P.; Taskinen, M.R.; Van Hul, W.; Mertens, I.; et al. PPAR $\alpha$ gene expression correlates with severity and histological treatment response in patients with non-alcoholic steatohepatitis. J. Hepatol. 2015, 63, 164-173. [CrossRef]

31. Rao, M.S.; Reddy, J.K. Peroxisomal $\beta$-oxidation and steatohepatitis. Semin. Liver Dis. 2001, 21, 43-55. [CrossRef]

32. Pérez-Carreras, M.; Del Hoyo, P.; Martín, M.A.; Rubio, J.C.; Martín, A.; Castellano, G.; Colina, F.; Arenas, J.; Solis-Herruzo, J.A. Defective hepatic mitochondrial respiratory chain in patients with nonalcoholic steatohepatitis. Hepatology 2003, 38, 999-1007. [CrossRef]

33. Koliaki, C.; Szendroedi, J.; Kaul, K.; Jelenik, T.; Nowotny, P.; Jankowiak, F.; Herder, C.; Carstensen, M.; Krausch, M.; Knoefel, W.T.; et al. Adaptation of Hepatic Mitochondrial Function in Humans with Non-Alcoholic Fatty Liver Is Lost in Steatohepatitis. Cell Metab. 2015, 21, 739-746. [CrossRef]

34. Kawano, Y.; Cohen, D.E. Mechanisms of hepatic triglyceride accumulation in non-alcoholic fatty liver disease. J. Gastroenterol. 2013, 48, 434-441. [CrossRef] [PubMed]

35. Siddoway, L.A.; Sloan, R.W. Amiodarone: Guidelines for Use and Monitoring. Am. Fam. Physician 2003, 68, 2189-2196.

36. Narayana, D.S.K.; Woods, D.D.R.; Boos, D.C.J. Management of Amiodarone-Related Thyroid Problems. Ther. Adv. Endocrinol. Metab. 2011, 2, 115. [CrossRef] [PubMed]

37. Ashrafian, H.; Horowitz, J.D.; Frenneaux, M.P. Perhexiline. Cardiovasc. Drug Rev. 2007, 25, 76-97. [CrossRef] [PubMed]

38. Inglis, S.; Stewart, S. Metabolic therapeutics in angina pectoris: History revisited with perhexiline. Eur. J. Cardiovasc. Nurs. 2006, 5, 175-184. [CrossRef] [PubMed]

39. Fromenty, B.; Pessayre, D. Impaired mitochondrial function in microvesicular steatosis: Effects of drugs, ethanol, hormones and cytokines. J. Hepatol. 1997, 26, 43-53. [CrossRef]

40. Fromenty, B.; Pessayre, D. Inhibition of mitochondrial beta-oxidation as a mechanism of hepatotoxicity. Pharmacol. Ther. 1995, 67, 101-154. [CrossRef]

41. Lewis, J.H.; Ranard, R.C.; Caruso, A.; Jackson, L.K.; Mullick, F.; Ishak, K.G.; Seeff, L.B.; Zimmerman, H.J. Amiodarone hepatotoxicity: Prevalence and clinicopathologic correlations among 104 patients. Hepatology 1989, 9, 679-685. [CrossRef]

42. Lewis, J.H.; Mullick, F.; Ishak, K.G.; Ranard, R.C.; Ragsdale, B.; Perse, R.M.; Rusnock, E.J.; Wolke, A.; Benjamin, S.B.; Seeff, L.B.; et al. Histopathologic analysis of suspected amiodarone hepatotoxicity. Hum. Pathol. 1990, 21, 59-67. [CrossRef]

43. Anthérieu, S.; Rogue, A.; Fromenty, B.; Guillouzo, A.; Robin, M.A. Induction of vesicular steatosis by amiodarone and tetracycline is associated with up-regulation of lipogenic genes in heparg cells. Hepatology 2011, 53, 1895-1905. [CrossRef] [PubMed]

44. Begriche, K.; Massart, J.; Robin, M.A.; Borgne-Sanchez, A.; Fromenty, B. Drug-induced toxicity on mitochondria and lipid metabolism: Mechanistic diversity and deleterious consequences for the liver. J. Hepatol. 2011, 54, 773-794. [CrossRef] [PubMed]

45. Deschamps, D.; DeBeco, V.; Fisch, C.; Fromenty, B.; Guillouzo, A.; Pessayre, D. Inhibition by perhexiline of oxidative phosphorylation and the $\beta$-oxidation of fatty acids: Possible role in pseudoalcoholic liver lesions. Hepatology 1994, 19, 948-961. [CrossRef] [PubMed]

46. Fromenty, B.; Fisch, C.; Berson, A.; Letteron, P.; Larrey, D.; Pessayre, D. Dual effect of amiodarone on mitochondrial respiration. Initial protonophoric uncoupling effect followed by inhibition of the respiratory chain at the levels of complex I and complex II. $J$. Pharmacol. Exp. Ther. 1990, 255, 1377-1384.

47. Spaniol, M.; Bracher, R.; Ha, H.R.; Follath, F.; Krähenbühl, S. Toxicity of amiodarone and amiodarone analogues on isolated rat liver mitochondria. J. Hepatol. 2001, 35, 628-636. [CrossRef]

48. Fromenty, B. Inhibition of mitochondrial fatty acid oxidation in drug-induced hepatic steatosis. Liver Res. 2019, 3, 157-169. [CrossRef]

49. Berson, A.; De Beco, V.; Letteron, P.; Robin, M.A.; Moreau, C.; El Kahwaji, J.; Verthier, N.; Feldmann, G.; Fromenty, B.; Pessayre, D. Steatohepatitis-inducing drugs cause mitochondrial dysfunction and lipid peroxidation in rat hepatocytes. Gastroenterology 1998 114, 764-774. [CrossRef]

50. Barclay, M.L.; Sawyers, S.M.; Begg, E.J.; Zhang, M.; Roberts, R.L.; Kennedy, M.A.; Elliott, J.M. Correlation of CYP2D6 genotype with perhexiline phenotypic metabolizer status. Pharmacogenetics 2003, 13, 627-632. [CrossRef]

51. Erez, N.; Hubel, E.; Avraham, R.; Cohen, R.; Fishman, S.; Bantel, H.; Manns, M.; Tirosh, B.; Zvibel, I.; Shibolet, O. Hepatic amiodarone lipotoxicity is ameliorated by genetic and pharmacological inhibition of endoplasmatic reticulum stress. Toxicol. Sci. 2017, 159, 402-412. [CrossRef]

52. Kudo, T.; Kanemoto, S.; Hara, H.; Morimoto, N.; Morihara, T.; Kimura, R.; Tabira, T.; Imaizumi, K.; Takeda, M. A molecular chaperone inducer protects neurons from ER stress. Cell Death Differ. 2008, 15, 364-375. [CrossRef]

53. Cataldi, M.; Citro, V.; Resnati, C.; Manco, F.; Tarantino, G. New Avenues for Treatment and Prevention of Drug-Induced Steatosis and Steatohepatitis: Much More Than Antioxidants. Adv. Ther. 2021, 38, 2094-2113. [CrossRef] [PubMed]

54. Zhou, F.; Zhang, Y.; Chen, J.; Hu, Y.; Xu, Y. Verapamil ameliorates hepatic metaflammation by inhibiting thioredoxin-interacting protein/NLRP3 pathways. Front. Endocrinol. 2018, 9, 640. [CrossRef]

55. Xu, D.; Wu, Y.; Liao, Z.X.; Wang, H. Protective effect of verapamil on multiple hepatotoxic factors-induced liver fibrosis in rats. Pharmacol. Res. 2007, 55, 280-286. [CrossRef] [PubMed]

56. Brookes, M.J.; Cooper, B.T. Hypertension and fatty liver: Guilty by association? J. Hum. Hypertens. 2007, 21, 264-270. [CrossRef]

57. Olivares-Reyes, J.A.; Arellano-Plancarte, A.; Castillo-Hernandez, J.R. Angiotensin II and the development of insulin resistance: Implications for diabetes. Mol. Cell. Endocrinol. 2009, 302, 128-139. [CrossRef] 
58. Bataller, R.; Sancho-Bru, P.; Ginès, P.; Lora, J.M.; Al-Garawi, A.; Solé, M.; Colmenero, J.; Nicolás, J.M.; Jiménez, W.; Weich, N.; et al. Activated human hepatic stellate cells express the renin-angiotensin system and synthesize angiotensin II. Gastroenterology 2003, 125, 117-125. [CrossRef]

59. Warner, F.J.; Lubel, J.S.; McCaughan, G.W.; Angus, P.W. Liver fibrosis: A balance of ACEs? Clin. Sci. 2007, 113, 109-118. [CrossRef]

60. Bataller, R.; Gäbele, E.; Parsons, C.J.; Morris, T.; Yang, L.; Schoonhoven, R.; Brenner, D.A.; Rippe, R.A. Systemic infusion of angiotensin II exacerbates liver fibrosis in bile duct-ligated rats. Hepatology 2005, 41, 1046-1055. [CrossRef] [PubMed]

61. Hirose, A.; Ono, M.; Saibara, T.; Nozaki, Y.; Masuda, K.; Yoshioka, A.; Takahashi, M.; Akisawa, N.; Iwasaki, S.; Oben, J.A.; et al. Angiotensin II type 1 receptor blocker inhibits fibrosis in rat nonalcoholic steatohepatitis. Hepatology 2007, 45, 1375-1381. [CrossRef] [PubMed]

62. Kurita, S.; Takamura, T.; Ota, T.; Matsuzawa-Nagata, N.; Kita, Y.; Uno, M.; Nabemoto, S.; Ishikura, K.; Misu, H.; Ando, H.; et al. Olmesartan ameliorates a dietary rat model of non-alcoholic steatohepatitis through its pleiotropic effects. Eur. J. Pharmacol. 2008, 588, 316-324. [CrossRef] [PubMed]

63. Kaji, K.; Yoshiji, H.; Kitade, M.; Ikenaka, Y.; Noguchi, R.; Shirai, Y.; Aihara, Y.; Namisaki, T.; Yoshii, J.; Yanase, K.; et al. Combination treatment of angiotensin II type I receptor blocker and new oral iron chelator attenuates progression of nonalcoholic steatohepatitis in rats. Am. J. Physiol. Gastrointest. Liver Physiol. 2011, 300, G1094-G1104. [CrossRef] [PubMed]

64. Yokohama, S.; Yoneda, M.; Haneda, M.; Okamoto, S.; Okada, M.; Aso, K.; Hasegawa, T.; Tokusashi, Y.; Miyokawa, N.; Nakamura, $\mathrm{K}$. Therapeutic efficacy of an angiotensin II receptor antagonist in patients with nonalcoholic steatohepatitis. Hepatology 2004, 40, 1222-1225. [CrossRef]

65. Shirai, Y.; Oda, S.; Makino, S.; Tsuneyama, K.; Yokoi, T. Establishment of a mouse model of enalapril-induced liver injury and investigation of the pathogenesis. Lab. Investig. 2017, 97, 833-842. [CrossRef]

66. da Silva, G.H.; Ribeiro Alves, A.V.F.; Duques, P.; Sevá-Pereira, T.; Soares, E.C.; Fazzio Escanhoela, C.A. View of Acute Hepatotoxicity Caused by Enalapril: A Case Report. Available online: https://www.jgld.ro/jgld/index.php/jgld/article/view/2010.2.10/925 (accessed on 7 September 2021).

67. Babany, G.; Uzzan, F.; Larrey, D.; Degott, C.; Bourgeois, P.; René, E.; Vissuzaine, C.; Erlinger, S.; Benhamou, J.-P. Alcoholic-like liver lesions induced by nifedipine. J. Hepatol. 1989, 9, 252-255. [CrossRef]

68. Nakagami, H.; Shimamura, M.; Miyake, T.; Shimosato, T.; Minobe, N.; Moritani, T.; Osako, M.K.; Nakagami, F.; Koriyama, H.; Kyutoku, M.; et al. Nifedipine prevents hepatic fibrosis in a non-alcoholic steatohepatitis model induced by an L-methionine-and choline-deficient diet. Mol. Med. Rep. 2012, 5, 37-40.

69. Wang, Y.; Nakajima, T.; Gonzalez, F.J.; Tanaka, N. PPARs as metabolic regulators in the liver: Lessons from liver-specific PPAR-null mice. Int. J. Mol. Sci. 2020, 21, 2061. [CrossRef]

70. Miyahara, T.; Schrum, L.; Rippe, R.; Xiong, S.; Yee, J.; Motomura, K.; Anania, F.A.; Willson, T.M.; Tsukamoto, H. Peroxisome Proliferator-activated Receptors and Hepatic Stellate Cell Activation *. J. Biol. Chem. 2000, 275, 35715-35722. [CrossRef]

71. Bae, M.A.; Rhee, S.D.; Jung, W.H.; Ahn, J.H.; Song, B.J.; Cheon, H.G. Selective inhibition of activated stellate cells and protection from carbon tetrachloride-induced liver injury in rats by a new PPARgamma agonist KR62776. Arch. Pharm. Res. 2010, 33, 433-442. [CrossRef] [PubMed]

72. Westphal, J.F.; Vetter, D.; Brogard, J.M. Hepatic side-effects of antibiotics. J. Antimicrob. Chemother. 1994, 33, 387-401. [CrossRef]

73. Fromenty, B. Alteration of mitochondrial DNA homeostasis in drug-induced liver injury. Food Chem. Toxicol. 2020, 135, 110916. [CrossRef]

74. Fréneaux, E.; Labbe, G.; Letteron, P.; Le Dinh, T.; Degott, C.; Genève, J.; Larrey, D.; Pessayre, D. Inhibition of the mitochondrial oxidation of fatty acids by tetracycline in mice and in man: Possible role in microvesicular steatosis induced by this antibiotic Hepatology 1988, 8, 1056-1062. [CrossRef]

75. Szalowska, E.; van der Burg, B.; Man, H.-Y.; Hendriksen, P.J.M.; Peijnenburg, A.A.C.M. Model Steatogenic Compounds (Amiodarone, Valproic Acid, and Tetracycline) Alter Lipid Metabolism by Different Mechanisms in Mouse Liver Slices. PLoS ONE 2014, 9, e86795. [CrossRef] [PubMed]

76. Breen, K.; Schenker, S.; Heimberg, M. The effect of tetracycline on the hepatic secretion of triglyceride. Biochim. Biophys. Acta-Lipids Lipid Metab. 1972, 270, 74-80. [CrossRef]

77. Lettéron, P.; Sutton, A.; Mansouri, A.; Fromenty, B.; Pessayre, D. Inhibition of microsomal triglyceride transfer protein: Another mechanism for drug-induced steatosis in mice. Hepatology 2003, 38, 133-140. [CrossRef]

78. Yin, H.Q.; Kim, M.; Kim, J.H.; Kong, G.; Lee, M.O.; Kang, K.S.; Yoon, B.I.L.; Kim, H.L.; Lee, B.H. Hepatic gene expression profiling and lipid homeostasis in mice exposed to seatogenic drug, tetracycline. Toxicol. Sci. 2006, 94, 206-216. [CrossRef] [PubMed]

79. Choi, Y.-J.; Lee, C.-H.; Lee, K.-Y.; Jung, S.-H.; Lee, B.-H. Increased Hepatic Fatty Acid Uptake and Esterification Contribute to Tetracycline-Induced Steatosis in Mice. Toxicol. Sci. 2015, 145, 273-282. [CrossRef]

80. Brüning, A.; Brem, G.J.; Vogel, M.; Mylonas, I. Tetracyclines cause cell stress-dependent ATF4 activation and mTOR inhibition. Exp. Cell Res. 2014, 320, 281-289. [CrossRef] [PubMed]

81. Deng, Z.; Yan, S.; Hu, H.; Duan, Z.; Yin, L.; Liao, S.; Sun, Y.; Yin, D.; Li, G. Proteomic profile of carbonylated proteins in rat liver: Discovering possible mechanisms for tetracycline-induced steatosis. Proteomics 2015, 15, 148-159. [CrossRef]

82. Santini, A.; Ronchi, D.; Garbellini, M.; Piga, D.; Protti, A. Linezolid-induced lactic acidosis: The thin line between bacterial and mitochondrial ribosomes. Expert Opin. Drug Saf. 2017, 16, 833-843. [CrossRef]

83. Vinh, D.C.; Rubinstein, E. Linezolid: A review of safety and tolerability. J. Infect. 2009, 59, S59-S74. [CrossRef] 
84. Leach, K.L.; Swaney, S.M.; Colca, J.R.; McDonald, W.G.; Blinn, J.R.; Thomasco, L.M.M.; Gadwood, R.C.; Shinabarger, D.; Xiong, L.; Mankin, A.S. The Site of Action of Oxazolidinone Antibiotics in Living Bacteria and in Human Mitochondria. Mol. Cell 2007, 26, 393-402. [CrossRef] [PubMed]

85. De Vriese, A.S.; Van Coster, R.; Smet, J.; Seneca, S.; Lovering, A.; Van Haute, L.L.; Vanopdenbosch, L.J.; Martin, J.-J.; Ceuterick-de Groote, C.; Vandecasteele, S.; et al. Linezolid-Induced Inhibition of Mitochondrial Protein Synthesis. Clin. Infect. Dis. 2006, 42, 1111-1117. [CrossRef]

86. Garrabou, G.; Soriano, A.; López, S.; Guallar, J.P.; Giralt, M.; Villarroya, F.; Martínez, J.A.; Casademont, J.; Cardellach, F.; Mensa, J.; et al. Reversible inhibition of mitochondrial protein synthesis during linezolid-related hyperlactatemia. Antimicrob. Agents Chemother. 2007, 51, 962-967. [CrossRef] [PubMed]

87. Le Guillou, D.; Bucher, S.; Begriche, K.; Hoët, D.; Lombès, A.; Labbe, G.; Fromenty, B. Drug-Induced Alterations of Mitochondrial DNA Homeostasis in Steatotic and Nonsteatotic HepaRG Cells. J. Pharmacol. Exp. Ther. 2018, 365, 711-726. [CrossRef]

88. De Bus, L.; Depuydt, P.; Libbrecht, L.; Vandekerckhove, L.; Nollet, J.; Benoit, D.; Vogelaers, D.; Van Vlierberghe, H. Severe Drug-induced Liver Injury Associated with Prolonged Use of Linezolid. J. Med. Toxicol. 2010, 6, 322-326. [CrossRef] [PubMed]

89. Huang, J.-H.; Zhang, C.; Zhang, D.-G.; Li, L.; Chen, X.; Xu, D.-X. Rifampicin-Induced Hepatic Lipid Accumulation: Association with Up-Regulation of Peroxisome Proliferator-Activated Receptor $\gamma$ in Mouse Liver. PLoS ONE 2016, 11, e0165787. [CrossRef] [PubMed]

90. Kazantzis, M.; Stahl, A. Fatty acid transport proteins, implications in physiology and disease. Biochim. Biophys. Acta-Mol. Cell Biol. Lipids 2012, 1821, 852-857. [CrossRef]

91. Pieper-Fürst, U.; Lammert, F. Low-density lipoprotein receptors in liver: Old acquaintances and a newcomer. Biochim. Biophys. Acta-Mol. Cell Biol. Lipids 2013, 1831, 1191-1198. [CrossRef]

92. Allard, J.; Bucher, S.; Massart, J.; Ferron, P.-J.; Le Guillou, D.; Loyant, R.; Daniel, Y.; Launay, Y.; Buron, N.; Begriche, K.; et al. Druginduced hepatic steatosis in absence of severe mitochondrial dysfunction in HepaRG cells: Proof of multiple mechanism-based toxicity. Cell Biol. Toxicol. 2020, 37, 151-175. [CrossRef] [PubMed]

93. Jordan, V.C. Tamoxifen: A most unlikely pioneering medicine. Nat. Rev. Drug Discov. 2003, 2, 205-213. [CrossRef]

94. Meunier, L.; Larrey, D. Chemotherapy-associated steatohepatitis. Ann. Hepatol. 2020, 19, 597-601. [CrossRef] [PubMed]

95. Saphner, T.; Triest-Robertson, S.; Li, H.; Holzman, P. The association of nonalcoholic steatohepatitis and tamoxifen in patients with breast cancer. Cancer 2009, 115, 3189-3195. [CrossRef] [PubMed]

96. Bruno, S.; Maisonneuve, P.; Castellana, P.; Rotmensz, N.; Rossi, S.; Maggioni, M.; Persico, M.; Colombo, A.; Monasterolo, F.; Casadei-Giunchi, D.; et al. Incidence and risk factors for non-alcoholic steatohepatitis: Prospective study of 5408 women enrolled in Italian tamoxifen chemoprevention trial. BMJ 2005, 330, 932. [CrossRef]

97. Chang, H.T.; Pan, H.J.; Lee, C.H. Prevention of Tamoxifen-related Nonalcoholic Fatty Liver Disease in Breast Cancer Patients Clin. Breast Cancer 2018, 18, e677-e685. [CrossRef]

98. Andrade, R.J.; Aithal, G.P.; Björnsson, E.S.; Kaplowitz, N.; Kullak-Ublick, G.A.; Larrey, D.; Karlsen, T.H. EASL Clinical Practice Guidelines: Drug-induced liver injury. J. Hepatol. 2019, 70, 1222-1261. [CrossRef] [PubMed]

99. Kumagai, S.; Holmäng, A.; Björntorp, P. The effects of oestrogen and progesterone on insulin sensitivity in female rats. Acta Physiol. Scand. 1993, 149, 91-97. [CrossRef] [PubMed]

100. Riant, E.; Waget, A.; Cogo, H.; Arnal, J.F.; Burcelin, R.; Gourdy, P. Estrogens protect against high-fat diet-induced insulin resistance and glucose intolerance in mice. Endocrinology 2009, 150, 2109-2117. [CrossRef]

101. Margolis, K.L.; Bonds, D.E.; Rodabough, R.J.; Tinker, L.; Phillips, L.S.; Allen, C.; Bassford, T.; Burke, G.; Torrens, J.; Howard, B.V Effect of oestrogen plus progestin on the incidence of diabetes in postmenopausal women: Results from the Women's Health Initiative Hormone Trial. Diabetologia 2004, 47, 1175-1187. [CrossRef]

102. McKenzie, J.; Fisher, B.M.; Jaap, A.J.; Stanley, A.; Paterson, K.; Sattar, N. Effects of HRT on liver enzyme levels in women with type 2 diabetes: A randomized placebo-controlled trial. Clin. Endocrinol. 2006, 65, 40-44. [CrossRef] [PubMed]

103. Venetsanaki, V.; Polyzos, S.A. Menopause and Non-Alcoholic Fatty Liver Disease: A Review Focusing on Therapeutic Perspectives. Curr. Vasc. Pharmacol. 2018, 17, 546-555. [CrossRef] [PubMed]

104. Ribas, V.; Nguyen, M.T.A.; Henstridge, D.C.; Nguyen, A.K.; Beaven, S.W.; Watt, M.J.; Hevener, A.L. Impaired oxidative metabolism and inflammation are associated with insulin resistance in ER $\alpha$-deficient mice. Am. J. Physiol.-Endocrinol. Metab. 2010, 298, E304-E319. [CrossRef] [PubMed]

105. Chow, J.D.Y.; Jones, M.E.E.; Prelle, K.; Simpson, E.R.; Boon, W.C. A selective estrogen receptor $\alpha$ agonist ameliorates hepatic steatosis in the male aromatase knockout mouse. J. Endocrinol. 2011, 210, 323-334. [CrossRef]

106. Ponnusamy, S.; Tran, Q.T.; Thiyagarajan, T.; Miller, D.D.; Bridges, D.; Narayanan, R. An estrogen receptor $\beta$-selective agonist inhibits non-alcoholic steatohepatitis in preclinical models by regulating bile acid and xenobiotic receptors. Exp. Biol. Med. 2017, 242, 606-616. [CrossRef] [PubMed]

107. Chen, J.Q.; Delannoy, M.; Cooke, C.; Yager, J.D. Mitochondrial localization of ER $\alpha$ and ER $\beta$ in human MCF7 cells. American J. Physiol.-Endocrinol. Metab. 2004, 286, 1011-1022. [CrossRef]

108. Maher, A.C.; Akhtar, M.; Tarnopolsky, M.A. Men supplemented with $17 \beta$-estradiol have increased $\beta$-oxidation capacity in skeletal muscle. Physiol. Genom. 2010, 42, 342-347. [CrossRef] 
109. Campbell, S.E.; Mehan, K.A.; Tunstall, R.J.; Febbraio, M.A.; Cameron-Smith, D. 17 $\beta$-Estradiol upregulates the expression of peroxisome proliferator-activated receptor $\alpha$ and lipid oxidative genes in skeletal muscle. J. Mol. Endocrinol. 2003, 31, 37-45. [CrossRef]

110. Zhou, Z.; Zhou, J.; Du, Y. Estrogen receptor alpha interacts with mitochondrial protein HADHB and affects beta-oxidation activity. Mol. Cell. Proteomics 2012, 11, M111-011056. [CrossRef]

111. Larosche, I.; Lettéron, P.; Fromenty, B.; Vadrot, N.; Abbey-Toby, A.; Feldmann, G.; Pessayre, D.; Mansouri, A. Tamoxifen inhibits topoisomerases, depletes mitochondrial DNA, and triggers steatosis in mouse liver. J. Pharmacol. Exp. Ther. 2007, 321, 526-535. [CrossRef] [PubMed]

112. Lelliott, C.J.; López, M.; Curtis, R.K.; Parker, N.; Laudes, M.; Yeo, G.; Jimenez-Liñan, M.; Grosse, J.; Saha, A.K.; Wiggins, D.; et al. Transcript and metabolite analysis of the effects of tamoxifen in rat liver reveals inhibition of fatty acid synthesis in the presence of hepatic steatosis. FASEB J. 2005, 19, 1108-1119. [CrossRef]

113. Zhao, F.; Xie, P.; Jiang, J.; Zhang, L.; An, W.; Zhan, Y. The Effect and Mechanism of Tamoxifen-Induced Hepatocyte Steatosis in Vitro. Int. J. Mol. Sci. 2014, 15, 4019-4030. [CrossRef]

114. Ohnishi, T.; Ogawa, Y.; Saibara, T.; Nishioka, A.; Kariya, S.; Fukumoto, M.; Onishi, S.; Yoshida, S. CYP17 polymorphism and tamoxifen-induced hepatic steatosis. Hepatol. Res. 2005, 33, 178-180. [CrossRef]

115. Yang, Y.J.; Kim, K.M.; An, J.H.; Lee, D.B.; Shim, J.H.; Lim, Y.S.; Lee, H.C.; Lee, Y.S.; Ahn, J.H.; Jung, K.H.; et al. Clinical significance of fatty liver disease induced by tamoxifen and toremifene in breast cancer patients. Breast 2016, 28, 67-72. [CrossRef]

116. Hamada, N.; Ogawa, Y.; Saibara, T.; Murata, Y.; Kariya, S.; Nishioka, A.; Terashima, M.; Inomata, T.; Yoshida, S. Toremifeneinduced fatty liver and NASH in breast cancer patients with breast-conservation treatment. Int. J. Oncol. 2000, 17, 1119-1142. [CrossRef]

117. Robinson, S.M.; Wilson, C.H.; Burt, A.D.; Manas, D.M.; White, S.A. Chemotherapy-Associated Liver Injury in Patients with Colorectal Liver Metastases: A Systematic Review and Meta-analysis. Ann. Surg. Oncol. 2012, 19, 4287-4299. [CrossRef] [PubMed]

118. Vauthey, J.-N.; Pawlik, T.M.; Ribero, D.; Wu, T.-T.; Zorzi, D.; Hoff, P.M.; Xiong, H.Q.; Eng, C.; Lauwers, G.Y.; Mino-Kenudson, M.; et al. Chemotherapy Regimen Predicts Steatohepatitis and an Increase in 90-Day Mortality After Surgery for Hepatic Colorectal Metastases. J. Clin. Oncol. 2016, 24, 2065-2072. [CrossRef]

119. Begriche, K.; Igoudjil, A.; Pessayre, D.; Fromenty, B. Mitochondrial dysfunction in NASH: Causes, consequences and possible means to prevent it. Mitochondrion 2006, 6, 1-28. [CrossRef] [PubMed]

120. Chun, Y.S.; Laurent, A.; Maru, D.; Vauthey, J.N. Management of chemotherapy-associated hepatotoxicity in colorectal liver metastases. Lancet Oncol. 2009, 10, 278-286. [CrossRef]

121. Fernandez, F.G.; Ritter, J.; Goodwin, J.W.; Linehan, D.C.; Hawkins, W.G.; Strasberg, S.M. Effect of steatohepatitis associated with irinotecan or oxaliplatin pretreatment on resectability of hepatic colorectal metastases. J. Am. Coll. Surg. 2005, 200, 845-853. [CrossRef]

122. Pilgrim, C.H.C.; Thomson, B.N.; Banting, S.; Phillips, W.A.; Michael, M. The developing clinical problem of chemotherapy-induced hepatic injury. ANZ J. Surg. 2012, 82, 23-29. [CrossRef] [PubMed]

123. Lehmann, K.; Rickenbacher, A.; Weber, A.; Pestalozzi, B.C.; Clavien, P.A. Chemotherapy before liver resection of colorectal metastases: Friend or foe? Ann. Surg. 2012, 255, 237-247. [CrossRef] [PubMed]

124. Sommer, J.; Mahli, A.; Freese, K.; Schiergens, T.S.; Kuecuekoktay, F.S.; Teufel, A.; Thasler, W.E.; Müller, M.; Bosserhoff, A.K.; Hellerbrand, C. Analysis of molecular mechanisms of 5-fluorouracil-induced steatosis and inflammation in vitro and in mice. Oncotarget 2017, 8, 13059. [CrossRef] [PubMed]

125. Win, S.; Than, T.A.; Le, B.H.A.; García-Ruiz, C.; Fernandez-Checa, J.C.; Kaplowitz, N. Sab (Sh3bp5) dependence of JNK mediated inhibition of mitochondrial respiration in palmitic acid induced hepatocyte lipotoxicity. J. Hepatol. 2015, 62, 1367-1374. [CrossRef]

126. Win, S.; Than, T.A.; Zhang, J.; Oo, C.; Min, R.W.M.; Kaplowitz, N. New insights into the role and mechanism of c-Jun-N-terminal kinase signaling in the pathobiology of liver diseases. Hepatology 2018, 67, 2013-2024. [CrossRef] [PubMed]

127. Win, S.; Than, T.A.; Min, R.W.M.; Aghajan, M.; Kaplowitz, N. c-Jun N-terminal kinase mediates mouse liver injury through a novel Sab (SH3BP5)-dependent pathway leading to inactivation of intramitochondrial Src. Hepatology 2016, 63, 1987-2003. [CrossRef] [PubMed]

128. Chambers, J.W.; LoGrasso, P.V. Mitochondrial c-Jun N-terminal kinase (JNK) signaling initiates physiological changes resulting in amplification of reactive oxygen species generation. J. Biol. Chem. 2011, 286, 16052-16062. [CrossRef]

129. Win, S.; Min, R.W.M.; Zhang, J.; Kanel, G.; Wanken, B.; Chen, Y.; Li, M.; Wang, Y.; Suzuki, A.; Aung, F.W.M.; et al. Hepatic Mitochondrial SAB Deletion or Knockdown Alleviates Diet-Induced Metabolic Syndrome, Steatohepatitis, and Hepatic Fibrosis. Hepatology 2021, 74, 3127-3145. [CrossRef]

130. Pilgrim, C.H.C.; Brettingham-Moore, K.; Pham, A.; Murray, W.; Link, E.; Smith, M.; Usatoff, V.; Evans, P.M.; Banting, S.; Thomson, B.N.; et al. MRNA gene expression correlates with histologically diagnosed chemotherapy-induced hepatic injury. HPB 2011, 13, 811-816. [CrossRef]

131. McWhirter, D.; Kitteringham, N.; Jones, R.P.; Malik, H.; Park, K.; Palmer, D. Chemotherapy induced hepatotoxicity in metastatic colorectal cancer: A review of mechanisms and outcomes. Crit. Rev. Oncol. Hematol. 2013, 88, 404-415. [CrossRef]

132. Horowitz, B.; Madras, B.K.; Meister, A.; Old, L.J.; Boyse, E.A.; Stockert, E. Asparagine synthetase activity of mouse leukemias. Science 1968, 160, 533-535. [CrossRef] [PubMed] 
133. Oettgen, H.F.; Tallal, L.; Tan, C.C.; Murphy, M.L.; Clarkson, B.D.; Golbey, R.D.; Krakoff, I.H.; Karnofsky, D.A.; Burchenal, H.J. Clinical experience with L-asparaginase. Recent Results Cancer Res. 1970, 33, 219-235. [PubMed]

134. Biggs, J.C.; Chestermant, C.N.; Holliday, J. L-asparaginase-Clinical Experience in Leukaemia, Lymphoma and Carcinoma. Aust. N. Z. J. Med. 1971, 1, 1-7. [CrossRef] [PubMed]

135. Distasio, J.A.; Salazar, A.M.; Nadji, M.; Durden, D.L. Glutaminase-free asparaginase from vibrio succinogenes: An antilymphoma enzyme lacking hepatotoxicity. Int. J. Cancer 1982, 30, 343-347. [CrossRef] [PubMed]

136. Sahoo, S.; Hart, J. Hstopathological features of L-asparaginase-induced liver disease. Semin. Liver Dis. 2003, 23, $295-299$.

137. Bodmer, M.; Sulz, M.; Stadlmann, S.; Droll, A.; Terracciano, L.; Krähenbühl, S. Fatal liver failure in an adult patient with acute lymphoblastic leukemia following treatment with L-asparaginase. Digestion 2006, 74, 28-32. [CrossRef]

138. Leonard, J.V.; Kay, J.D.S. Acute encephalopathy and hyperammonaemia complicating treatment of acute lymphoblastic leukaemia with asparaginase. Lancet 1986, 327, 162-163. [CrossRef]

139. Lee, A.U.; Farrell, G.C. Mechanism of azathioprine-induced injury to hepatocytes: Roles of glutathione depletion and mitochondrial injury. J. Hepatol. 2001, 35, 756-764. [CrossRef]

140. Vairetti, M.; Di Pasqua, L.G.; Cagna, M.; Richelmi, P.; Ferrigno, A.; Berardo, C. Changes in Glutathione Content in Liver Diseases: An Update. Antioxidants 2021, 10, 364. [CrossRef] [PubMed]

141. Raabe, M.; Véniant, M.M.; Sullivan, M.A.; Zlot, C.H.; Björkegren, J.; Nielsen, L.B.; Wong, J.S.; Hamilton, R.L.; Young, S.G. Analysis of the role of microsomal triglyceride transfer protein in the liver of tissue-specific knockout mice. J. Clin. Investig. 1999, 103, 1287-1298. [CrossRef]

142. Lewis, J.H.; Schiff, E. Methotrexate-induced chronic liver injury: Guidelines for detection and prevention. The ACG Committee on FDA-related matters. American College of Gastroenterology. Am. J. Gastroenterol. 1988, 83, 1337-13345. [PubMed]

143. Yamamoto, N.; Oliveira, M.B.M.; Campello, A.D.P.; Lopes, L.C.V.; Klüppel, M.L.W. Methotrexate: Studies on the cellular metabolism. I. Effect on mitochondrial oxygen uptake and oxidative phosphorylation. Cell Biochem. Funct. 1988, 6, 61-66. [CrossRef]

144. Caetano, N.N.; Campello, A.P.; Carnieri, E.G.S.; Kluppel, M.L.W.; Oliveira, M.B.M. Effect of methotrexate (MTX) on NAD(P)+ dehydrogenases of HeLa cells: Malic enzyme, 2-oxoglutarate and isocitrate dehydrogenases. Cell Biochem. Funct. 1997, 15, 259-264. [CrossRef]

145. Kim, J.; Lowe, K.; Chemistry, B.S.-J. Regulation of folate and one-carbon metabolism in mammalian cells. IV. Role of folylpolygamma-glutamate synthetase in methotrexate metabolism and cytotoxicity. J. Biol. Chem. 1993, 268, 21680-21685. [CrossRef]

146. Huang, C.C.; Hsu, P.C.; Hung, Y.C.; Liao, Y.F.; Liu, C.C.; Hour, C.T.; Kao, M.C.; Tsay, G.J.; Hung, H.C.; Liu, G.Y. Ornithine decarboxylase prevents methotrexate-induced apoptosis by reducing intracellular reactive oxygen species production. Apoptosis 2005, 10, 895-907. [CrossRef] [PubMed]

147. Tabassum, H.; Parvez, S.; Pasha, S.T.; Banerjee, B.D.; Raisuddin, S. Protective effect of lipoic acid against methotrexate-induced oxidative stress in liver mitochondria. Food Chem. Toxicol. 2010, 48, 1973-1979. [CrossRef] [PubMed]

148. Song, D.; Shi, B.; Xue, H.; Li, Y.; Yang, X.; Yu, B.; Xu, Z.; Liu, F.; Li, J. Confirmation and Prevention of Intestinal Barrier Dysfunction and Bacterial Translocation Caused by Methotrexate. Dig. Dis. Sci. 2006, 51, 1549-1556. [CrossRef]

149. Cronstein, B.N.; Eberle, M.A.; Gruber, H.E.; Levin, R.I. Methotrexate inhibits neutrophil function by stimulating adenosine release from connective tissue cells. Proc. Natl. Acad. Sci. USA 1991, 88, 2441-2445. [CrossRef]

150. Chan, E.S.L.; Montesinos, M.C.; Fernandez, P.; Desai, A.; Delano, D.L.; Yee, H.; Reiss, A.B.; Pillinger, M.H.; Chen, J.F.; Schwarzschild, M.A.; et al. Adenosine A 2A receptors play a role in the pathogenesis of hepatic cirrhosis. Br. J. Pharmacol. 2006, 148, 1144-1155. [CrossRef]

151. Romoli, M.; Mazzocchetti, P.; D’Alonzo, R.; Siliquini, S.; Rinaldi, V.E.; Verrotti, A.; Calabresi, P.; Costa, C. Valproic Acid and Epilepsy: From Molecular Mechanisms to Clinical Evidences. Curr. Neuropharmacol. 2018, 17, 926-946. [CrossRef]

152. Rakitin, A. Does valproic acid have potential in the treatment of diabetes mellitus? Front. Endocrinol. 2017, 8, 147. [CrossRef] [PubMed]

153. Brown, B.L.; Craycraft, L.K.; Justice, S.B. Valproic Acid in the Treatment of Migraines. Adv. Emerg. Nurs. J. 2020, 42, $243-253$. [CrossRef]

154. Elshafay, A.; Hieu, T.H.; Doheim, M.F.; Kassem, M.A.M.; ELdoadoa, M.F.; Holloway, S.K.; Abo-elghar, H.; Hirayama, K.; Huy, N.T. Efficacy and Safety of Valproic Acid for Spinal Muscular Atrophy: A Systematic Review and Meta-Analysis. CNS Drugs 2019, 33, 239-250. [CrossRef]

155. Laengle, J.; Kabiljo, J.; Hunter, L.; Homola, J.; Prodinger, S.; Egger, G.; Bergmann, M. Histone deacetylase inhibitors valproic acid and vorinostat enhance trastuzumab-mediated antibody-dependent cell-mediated phagocytosis. J. Immunother. Cancer 2020, 8 , e000195. [CrossRef] [PubMed]

156. Caponigro, F.; Di Gennaro, E.; Ionna, F.; Longo, F.; Aversa, C.; Pavone, E.; Maglione, M.G.; Di Marzo, M.; Muto, P.; Cavalcanti, E.; et al. Phase II clinical study of valproic acid plus cisplatin and cetuximab in recurrent and/or metastatic squamous cell carcinoma of Head and Neck-V-CHANCE trial. BMC Cancer 2016, 16, 918. [CrossRef]

157. Lin, T.; Ren, Q.; Zuo, W.; Jia, R.; Xie, L.; Lin, R.; Zhao, H.; Chen, J.; Lei, Y.; Wang, P.; et al. Valproic acid exhibits anti-tumor activity selectively against EGFR/ErbB2/ErbB3-coexpressing pancreatic cancer via induction of ErbB family members-targeting microRNAs. J. Exp. Clin. Cancer Res. 2019, 38, 150. [CrossRef] 
158. Farinelli, E.; Giampaoli, D.; Cenciarini, A.; Cercado, E.; Verrotti, A. Valproic acid and nonalcoholic fatty liver disease: A possible association? World J. Hepatol. 2015, 7, 1251-1257. [CrossRef] [PubMed]

159. Guo, H.-L.; Jing, X.; Sun, J.-Y.; Hu, Y.; Xu, Z.-J.; Ni, M.-M.; Chen, F.; Lu, X.-P.; Qiu, J.-C.; Wang, T. Valproic Acid and the Liver Injury in Patients with Epilepsy: An Update. Curr. Pharm. Des. 2019, 25, 343-351. [CrossRef] [PubMed]

160. Bowden, C. Valproate. Natl. Inst. Diabetes Dig. Kidney Dis. 2003, 5, 189-202. [CrossRef]

161. Aires, C.C.P.; IJlst, L.; Stet, F.; Prip-Buus, C.; de Almeida, I.T.; Duran, M.; Wanders, R.J.A.; Silva, M.F.B. Inhibition of hepatic carnitine palmitoyl-transferase I (CPT IA) by valproyl-CoA as a possible mechanism of valproate-induced steatosis. Biochem. Pharmacol. 2010, 79, 792-799. [CrossRef] [PubMed]

162. Aires, C.C.P.; Soveral, G.; Luís, P.B.M.; ten Brink, H.J.; de Almeida, I.T.; Duran, M.; Wanders, R.J.A.; Silva, M.F.B. Pyruvate uptake is inhibited by valproic acid and metabolites in mitochondrial membranes. FEBS Lett. 2008, 582, 3359-3366. [CrossRef]

163. Caiment, F.; Wolters, J.; Smit, E.; Schrooders, Y.; Kleinjans, J.; van den Beucken, T. Valproic acid promotes mitochondrial dysfunction in primary human hepatocytes in vitro; impact of $\mathrm{C} / \mathrm{EBP} \alpha$-controlled gene expression. Arch. Toxicol. 2020, 94, 3463-3473. [CrossRef]

164. van Breda, S.G.J.; Claessen, S.M.H.; van Herwijnen, M.; Theunissen, D.H.J.; Jennen, D.G.J.; de Kok, T.M.C.M.; Kleinjans, J.C.S Integrative omics data analyses of repeated dose toxicity of valproic acid in vitro reveal new mechanisms of steatosis induction Toxicology 2018, 393, 160-170. [CrossRef] [PubMed]

165. Pourahmad, J.; Eskandari, M.R.; Kaghazi, A.; Shaki, F.; Shahraki, J.; Fard, J.K. A new approach on valproic acid induced hepatotoxicity: Involvement of lysosomal membrane leakiness and cellular proteolysis. Toxicol. Vitr. 2012, 26, 545-551. [CrossRef] [PubMed]

166. Palsamy, P.; Bidasee, K.R.; Shinohara, T. Valproic acid suppresses Nrf2/Keap1 dependent antioxidant protection through induction of endoplasmic reticulum stress and Keap1 promoter DNA demethylation in human lens epithelial cells. Exp. Eye Res. 2014, 121, 26. [CrossRef] [PubMed]

167. Ahangar, N.; Naderi, M.; Noroozi, A.; Ghasemi, M.; Zamani, E.; Shaki, F. Zinc Deficiency and Oxidative Stress Involved in Valproic Acid Induced Hepatotoxicity: Protection by Zinc and Selenium Supplementation. Biol. Trace Elem. Res. 2017, 179, 102-109. [CrossRef]

168. Gai, Z.; Krajnc, E.; Samodelov, S.L.; Visentin, M.; Kullak-Ublick, G.A. Obeticholic acid ameliorates valproic acid-induced hepatic steatosis and oxidative stress. Mol. Pharmacol. 2020, 97, 314-323. [CrossRef] [PubMed]

169. Grieco, A.; Alfei, B.; Di Rocco, P.; Miele, L.; Biolcati, G.; Griso, D.; Vecchio, F.M.; Bianco, A.; Gasbarrini, G. Non-alcoholic steatohepatitis induced by carbamazepine and variegate porphyria. Eur. J. Gastroenterol. Hepatol. 2001, 13, 973-975. [CrossRef] [PubMed]

170. Lillibridge, J.H.; Amore, B.M.; Slattery, J.T.; Kalhorn, T.F.; Nelson, S.D.; Finnell, R.H.; Bennett, G.D. Protein-reactive metabolites of carbamazepine in mouse liver microsomes. Drug Metab. Dispos. 1996, 24, 509-514.

171. Hamed, S.A.; Fathy, R.A.; Radwan, M.E.; Abdellah, M.M. Fatty liver in adults receiving antiepileptic medications: Relationship to the metabolic risks. Expert Rev. Clin. Pharmacol. 2016, 9, 617-624. [CrossRef]

172. Rhen, T.; Cidlowski, J.A. Antiinflammatory Action of Glucocorticoids-New Mechanisms for Old Drugs. N. Engl. J. Med. 2005, 353, 1711-1723. [CrossRef]

173. Schäcke, H.; Döcke, W.D.; Asadullah, K. Mechanisms involved in the side effects of glucocorticoids. Pharmacol. Ther. 2002, 96, 23-43. [CrossRef]

174. Ramamoorthy, S.; Cidlowski, J.A. Corticosteroids-Mechanisms of Action in Health and Disease. Rheum. Dis. Clin. N. Am. 2016, 42, 15. [CrossRef]

175. Rahimi, L.; Rajpal, A.; Ismail-Beigi, F. Glucocorticoid-Induced Fatty Liver Disease. Diabetes Metab. Syndr. Obes. Targets Ther. 2020, 13, 1133. [CrossRef]

176. Shibli-Rahhal, A.; Van Beek, M.; Schlechte, J.A. Cushing's syndrome. Clin. Dermatol. 2006, 24, 260-265. [CrossRef] [PubMed]

177. Chanson, P.; Salenave, S. Metabolic syndrome in Cushing's syndrome. Neuroendocrinology 2010, 92, 96-101. [CrossRef] [PubMed]

178. Uddén, J.; Björntorp, P.; Arner, P.; Barkeling, B.; Meurling, L.; Rössner, S. Effects of glucocorticoids on leptin levels and eating behaviour in women. J. Intern. Med. 2003, 253, 225-231. [CrossRef]

179. Solano, J.M.; Jacobson, L. Glucocorticoids reverse leptin effects on food intake and body fat in mice without increasing NPY mRNA. Am. J. Physiol.-Endocrinol. Metab. 1999, 277, E708-E716. [CrossRef]

180. Perry, R.J.; Resch, J.M.; Douglass, A.M.; Madara, J.C.; Rabin-Court, A.; Kucukdereli, H.; Wu, C.; Song, J.D.; Lowell, B.B.; Shulman, G.I. Leptin's hunger-suppressing effects are mediated by the hypothalamic-pituitary-adrenocortical axis in rodents. Proc. Natl. Acad. Sci. USA 2019, 116, 13670-13679. [CrossRef]

181. Ishida-Takahashi, R.; Uotani, S.; Abe, T.; Degawa-Yamauchi, M.; Fukushima, T.; Fujita, N.; Sakamaki, H.; Yamasaki, H.; Yamaguchi, Y.; Eguchi, K. Rapid Inhibition of Leptin Signaling by Glucocorticoids in Vitro and in Vivo. J. Biol. Chem. 2004, 279, 19658-19664. [CrossRef]

182. Weickert, M.O.; Pfeiffer, A.F.H. Signalling mechanisms linking hepatic glucose and lipid metabolism. Diabetologia 2006, 49 , 1732-1741. [CrossRef] [PubMed]

183. Puigserver, P.; Rhee, J.; Donovan, J.; Walkey, C.J.; Yoon, J.C.; Oriente, F.; Kitamura, Y.; Altomonte, J.; Dong, H.; Accili, D.; et al Insulin-regulated hepatic gluconeogenesis through FOXO1-PGC-1 $\alpha$ interaction. Nature 2003, 423, 550-555. [CrossRef] [PubMed] 
184. Dentin, R.; Pégorier, J.P.; Benhamed, F.; Foufelle, F.; Ferré, P.; Fauveau, V.; Magnuson, M.A.; Girard, J.; Postic, C. Hepatic Glucokinase Is Required for the Synergistic Action of ChREBP and SREBP-1c on Glycolytic and Lipogenic Gene Expression. J. Biol. Chem. 2004, 279, 20314-20326. [CrossRef] [PubMed]

185. Feng, B.; He, Q.; Xu, H. FOXO1-dependent up-regulation of MAP kinase phosphatase 3 (MKP-3) mediates glucocorticoid-induced hepatic lipid accumulation in mice. Mol. Cell. Endocrinol. 2014, 393, 46-55. [CrossRef]

186. D’Souza, A.M.; Beaudry, J.L.; Szigiato, A.A.; Trumble, S.J.; Snook, L.A.; Bonen, A.; Giacca, A.; Riddell, M.C. Consumption of a high-fat diet rapidly exacerbates the development of fatty liver disease that occurs with chronically elevated glucocorticoids. Am. J. Physiol.-Gastrointest. Liver Physiol. 2012, 302, G850-G863. [CrossRef]

187. Dolinsky, V.W.; Douglas, D.N.; Lehner, R.; Vance, D.E. Regulation of the enzymes of hepatic microsomal triacylglycerol lipolysis and re-esterification by the glucocorticoid dexamethasone. Biochem. J. 2004, 378, 967-974. [CrossRef]

188. Marino, J.S.; Stechschulte, L.A.; Stec, D.E.; Nestor-Kalinoski, A.; Coleman, S.; Hinds, T.D., Jr. Glucocorticoid Receptor $\beta$ Induces Hepatic Steatosis by Augmenting Inflammation and Inhibition of the Peroxisome Proliferator-activated Receptor (PPAR) $\alpha$. J. Biol. Chem. 2016, 291, 25776. [CrossRef] [PubMed]

189. Jia, Y.; Viswakarma, N.; Fu, T.; Yu, S.; Rao, M.S.; Borensztajn, J.; Reddy, J.K. Conditional ablation of mediator subunit MED1 (MED1/PPARBP) gene in mouse liver attenuates glucocorticoid receptor agonist dexamethasone-induced hepatic steatosis. Gene Expr. 2009, 14, 291-306. [CrossRef]

190. Chen, T.-C.; Lee, R.A.; Tsai, S.L.; Kanamaluru, D.; Gray, N.E.; Yiv, N.; Cheang, R.T.; Tan, J.H.; Lee, J.Y.; Fitch, M.D.; et al. An ANGPTL4-ceramide-protein kinase $\mathrm{C} \zeta$ axis mediates chronic glucocorticoid exposure-induced hepatic steatosis and hypertriglyceridemia in mice. J. Biol. Chem. 2019, 294, 9213-9224. [CrossRef]

191. Utzeri, E.; Usai, P. Role of non-steroidal anti-inflammatory drugs on intestinal permeability and nonalcoholic fatty liver disease. World J. Gastroenterol. 2017, 23, 3954. [CrossRef]

192. Bjarnason, I.; Scarpignato, C.; Holmgren, E.; Olszewski, M.; Rainsford, K.D.; Lanas, A. Mechanisms of Damage to the Gastrointestinal Tract from Nonsteroidal Anti-Inflammatory Drugs. Gastroenterology 2018, 154, 500-514. [CrossRef] [PubMed]

193. Adebayo, D.; Bjarnason, I. Is non-steroidal anti-inflammaory drug (NSAID) enteropathy clinically more important than NSAID gastropathy? Postgrad. Med. J. 2006, 82, 186-191. [CrossRef]

194. Lanas, A.; Panes, J.; Pique, J. Clinical Implications of COX-1 and / or COX-2 Inhibition for the Distal Gastrointestinal Tract. Curr. Pharm. Des. 2005, 9, 2253-2266. [CrossRef] [PubMed]

195. Graham, D.Y.; Opekun, A.R.; Willingham, F.F.; Qureshi, W.A. Visible small-intestinal mucosal injury in chronic NSAID users Clin. Gastroenterol. Hepatol. 2005, 3, 55-59. [CrossRef]

196. Lanas, A.; Sopeña, F. Nonsteroidal Anti-Inflammatory Drugs and Lower Gastrointestinal Complications. Gastroenterol. Clin. N. Am. 2009, 38, 333-352. [CrossRef]

197. Bjarnason, I.; Hayllar, J.; Macpherson, A.N.d.J.; Russell, A.N.t.S. Side effects of nonsteroidal anti-inflammatory drugs on the small and large intestine in humans. Gastroenterology 1993, 104, 1832-1847. [CrossRef]

198. Bessone, F. Non-steroidal anti-inflammatory drugs: What is the actual risk of liver damage? World J. Gastroenterol. 2010, 16, 5651. [CrossRef]

199. Doi, H.; Horie, T. Salicylic acid-induced hepatotoxicity triggered by oxidative stress. Chem. Biol. Interact. 2010, 183, 363-368. [CrossRef] [PubMed]

200. Fujita, K.; Nozaki, Y.; Wada, K.; Yoneda, M.; Endo, H.; Takahashi, H.; Iwasaki, T.; Inamori, M.; Abe, Y.; Kobayashi, N.; et al. Effectiveness of antiplatelet drugs against experimental non-alcoholic fatty liver disease. Gut 2008, 57, 1583-1591. [CrossRef]

201. Ibrahim, M.; Farghaly, E.; Gomaa, W.; Kelleni, M.; Abdelrahman, A.M. Nitro-aspirin is a potential therapy for non alcoholic fatty liver disease. Eur. J. Pharmacol. 2011, 659, 289-295. [CrossRef]

202. Shen, H.; Shahzad, G.; Jawairia, M.; Bostick, R.M.; Mustacchia, P. Association between aspirin use and the prevalence of nonalcoholic fatty liver disease: A cross-sectional study from the Third National Health and Nutrition Examination Survey. Aliment. Pharmacol. Ther. 2014, 40, 1066-1073. [CrossRef]

203. Murohara, T.; Horowitz, J.R.; Silver, M.; Tsurumi, Y.; Chen, D.; Sullivan, A.; Isner, J.M. Vascular endothelial growth factor/vascular permeability factor enhances vascular permeability via nitric oxide and prostacyclin. Circulation 1998, 97, 99-107. [CrossRef]

204. Sánchez De Miguel, L.; De Frutos, T.; González-Fernández, F.; Del Pozo, V.; Lahoz, C.; Jiménez, A.; Rico, L.; García, R.; Aceituno, E.; Millás, I.; et al. Aspirin inhibits inducible nitric oxide synthase expression and tumour necrosis factor- $\alpha$ release by cultured smooth muscle cells. Eur. J. Clin. Investig. 1999, 29, 93-99. [CrossRef] [PubMed]

205. Campbell, J.S.; Hughes, S.D.; Gilbertson, D.G.; Palmer, T.E.; Holdren, M.S.; Haran, A.C.; Odell, M.M.; Bauer, R.L.; Ren, H.P.; Haugen, H.S.; et al. Platelet-derived growth factor $\mathrm{C}$ induces liver fibrosis, steatosis, and hepatocellular carcinoma. Proc. Natl. Acad. Sci. USA 2005, 102, 3389-3394. [CrossRef]

206. Tarantino, G.; Caputi, A. JNKs, insulin resistance and inflammation: A possible link between NAFLD and coronary artery disease. World J. Gastroenterol. 2011, 17, 3785-3794. [CrossRef]

207. Simon, T.G.; Henson, J.; Osganian, S.; Masia, R.; Chan, A.T.; Chung, R.T.; Corey, K.E. Daily Aspirin Use Associated With Reduced Risk For Fibrosis Progression In Patients With Nonalcoholic Fatty Liver Disease. Clin. Gastroenterol. Hepatol. 2019, 17, $2776-2784$. [CrossRef]

208. García-Román, R.; Francés, R. Acetaminophen-Induced Liver Damage in Hepatic Steatosis. Clin. Pharmacol. Ther. 2020, 107, 1068-1081. [CrossRef] 
209. Kučera, O.; Al-Dury, S.; Lotková, H.; Roǔar, T.; Rychtrmoc, D.; Červinková, Z. Steatotic rat hepatocytes in primary culture are more susceptible to the acute toxic effect of acetaminophen. Physiol. Res. 2012, 61, S93. [CrossRef] [PubMed]

210. Chen, C.; Krausz, K.W.; Shah, Y.M.; Idle, J.R.; Gonzalez, F.J. Serum Metabolomics Reveals Irreversible Inhibition of Fatty Acid $\beta$-Oxidation through the Suppression of PPAR $\alpha$ Activation as a Contributing Mechanism of Acetaminophen-Induced Hepatotoxicity. Chem. Res. Toxicol. 2009, 22, 699-707. [CrossRef] [PubMed]

211. Bhattacharyya, S.; Pence, L.; Beger, R.; Chaudhuri, S.; McCullough, S.; Yan, K.; Simpson, P.; Hennings, L.; Hinson, J.; James, L. Acylcarnitine Profiles in Acetaminophen Toxicity in the Mouse: Comparison to Toxicity, Metabolism and Hepatocyte Regeneration. Metabolites 2013, 3, 606-622. [CrossRef] [PubMed]

212. McGill, M.R.; Li, F.; Sharpe, M.R.; Williams, C.D.; Curry, S.C.; Ma, X.; Jaeschke, H. Circulating acylcarnitines as biomarkers of mitochondrial dysfunction after acetaminophen overdose in mice and humans. Arch. Toxicol. 2013, 88, 391-401. [CrossRef] [PubMed]

213. Sim, K.G.; Carpenter, K.; Hammond, J.; Christodoulou, J.; Wilcken, B. Acylcarnitine profiles in fibroblasts from patients with respiratory chain defects can resemble those from patients with mitochondrial fatty acid [beta ]-oxidation disorders. Metabolism 2002, 51, 366-371. [CrossRef] [PubMed]

214. Aubert, J.; Begriche, K.; Delannoy, M.; Morel, I.; Pajaud, J.; Ribault, C.; Lepage, S.; McGill, M.R.; Lucas-Clerc, C.; Turlin, B.; et al. Differences in Early Acetaminophen Hepatotoxicity between Obese ob/ob and db/db Mice. J. Pharmacol. Exp. Ther. 2012, 342, 676-687. [CrossRef] [PubMed]

215. Li, D.; Du, Y.; Yuan, X.; Han, X.; Dong, Z.; Chen, X.; Wu, H.; Zhang, J.; Xu, L.; Han, C.; et al. Hepatic hypoxia-inducible factors inhibit PPAR $\alpha$ expression to exacerbate acetaminophen induced oxidative stress and hepatotoxicity. Free Radic. Biol. Med. 2017, 110, 102-116. [CrossRef]

216. Geneve, J.; Hayat-Bonan, B.; Labbe, G.; Degott, C.; Letteron, P.; Freneaux, E.; Dinh, T.L.; Larrey, D.; Pessayre, D. Inhibition of mitochondrial beta-oxidation of fatty acids by pirprofen. Role in microvesicular steatosis due to this nonsteroidal antiinflammatory drug. J. Pharmacol. Exp. Ther. 1987, 242, 1133-1137.

217. Freneaux, E.; Fromenty, B.; Berson, A.; Labbe, G.; Degott, C.; Letteron, P.; Larrey, D.; Pessayre, D. Stereoselective and nonstereoselective effects of ibuprofen enantiomers on mitochondrial beta-oxidation of fatty acids. J. Pharmacol. Exp. Ther. 1990, 255.

218. Caldwell, J.; Hutt, A.J.; Fournel-Gigleux, S. The metabolic chiral inversion and dispositional enantioselectivity of the 2arylpropionic acids and their biological consequences. Biochem. Pharmacol. 1988, 37, 105-114. [CrossRef]

219. Caldwell, J. Xenobiotic acyl-coenzymes A: Critical intermediates in the biochemical pharmacology and toxicology of carboxylic acids. Biochem. Soc. Trans. 1984, 12, 9-11. [CrossRef]

220. Williams, K.; Day, R.; Knihinicki, R.; Duffield, A. The stereoselective uptake of ibuprofen enantiomers into adipose tissue. Biochem. Pharmacol. 1986, 35, 3403-3405. [CrossRef]

221. Lu, W.; Cheng, F.; Jiang, J.; Zhang, C.; Deng, X.; Xu, Z.; Zou, S.; Shen, X.; Tang, Y.; Huang, J. FXR antagonism of NSAIDs contributes to drug-induced liver injury identified by systems pharmacology approach. Sci. Rep. 2015, 5, 8114. [CrossRef]

222. Massart, J.; Begriche, K.; Buron, N.; Porceddu, M.; Borgne-Sanchez, A.; Fromenty, B. Drug-Induced Inhibition of Mitochondrial Fatty Acid Oxidation and Steatosis. Curr. Pathobiol. Rep. 2013, 1, 147-157. [CrossRef]

223. Patel, V.; Sanyal, A.J. Drug-induced steatohepatitis. Clin. Liver Dis. 2013, 17, 533-546. [CrossRef] [PubMed]

224. Famularo, G.; Gasbarrone, L.; Minisola, G. Probable ketoprofen-associated nonalcoholic fatty liver disease and steatohepatitis. Ann. Pharmacother. 2011, 45, 423. [CrossRef] [PubMed]

225. Montessori, V.; Harris, M.; Montaner, J.S.G. Hepatotoxicity of nucleoside reverse transcriptase inhibitors. Semin. Liver Dis. 2003, 23, 167-171.

226. Guaraldi, G.; Squillace, N.; Stentarelli, C.; Orlando, G.; D'Amico, R.; Ligabue, G.; Fiocchi, F.; Zona, S.; Loria, P.; Esposito, R.; et al. Nonalcoholic fatty liver disease in HIV-infected patients referred to a metabolic clinic: Prevalence, characteristics, and predictors. Clin. Infect. Dis. 2008, 47, 250-257. [CrossRef] [PubMed]

227. Crum-Cianflone, N.; Dilay, A.; Collins, G.; Asher, D.; Campin, R.; Medina, S.; Goodman, Z.; Parker, R.; Lifson, A.; Capozza, T.; et al. Nonalcoholic Fatty Liver Disease (NAFLD) among HIV-Infected Persons. J. Acquir. Immune Defic. Syndr. 2009, 50, 464 [CrossRef] [PubMed]

228. Furman, P.A.; Fyfe, J.A.; St Clair, M.H.; Weinhold, K.; Rideout, J.L.; Freeman, G.A.; Lehrman, S.N.; Bolognesi, D.P.; Broder, S.; Mitsuya, H. Phosphorylation of 3'-azido-3'-deoxythymidine and selective interaction of the 5'-triphosphate with human immunodeficiency virus reverse transcriptase. Proc. Natl. Acad. Sci. USA 1986, 83, 8333-8337. [CrossRef]

229. Lewis, W.; Dalakas, M.C. Mitochondrial toxicity of antiviral drugs. Nat. Med. 1995, 1, 417-422. [CrossRef]

230. Johnson, A.A.; Ray, A.S.; Hanes, J.; Suo, Z.; Colacino, J.M.; Anderson, K.S.; Johnson, K.A. Toxicity of Antiviral Nucleoside Analogs and the Human Mitochondrial DNA Polymerase. J. Biol. Chem. 2001, 276, 40847-40857. [CrossRef] [PubMed]

231. Price, J.C.; Thio, C.L. Liver Disease in the HIV-Infected Individual. Clin. Gastroenterol. Hepatol. 2010, 8, 1002. [CrossRef] [PubMed]

232. Banerjee, A.; Abdelmegeed, M.A.; Jang, S.; Song, B.-J. Zidovudine (AZT) and Hepatic Lipid Accumulation: Implication of Inflammation, Oxidative and Endoplasmic Reticulum Stress Mediators. PLoS ONE 2013, 8, e76850.

233. Stankov, M.V.; Panayotova-Dimitrova, D.; Leverkus, M.; Vondran, F.W.R.; Bauerfeind, R.; Binz, A.; Behrens, G.M.N. Autophagy inhibition due to thymidine analogues as novel mechanism leading to hepatocyte dysfunction and lipid accumulation. AIDS 2012, 26, 1995-2006. [CrossRef] [PubMed] 
234. Coronel-Castillo, C.E.; Qi, X.; Contreras-Carmona, J.; Ramírez-Pérez, O.L.; Méndez-Sánchez, N. Nonalcoholic fatty liver disease and nonalcoholic steatohepatitis in HIV infection: A metabolic approach of an infectious disease. Expert Rev. Gastroenterol. Hepatol. 2019, 13, 531-540. [CrossRef] [PubMed]

235. Sun, R.; Eriksson, S.; Wang, L. Down-regulation of mitochondrial thymidine kinase 2 and deoxyguanosine kinase by didanosine: Implication for mitochondrial toxicities of anti-HIV nucleoside analogs. Biochem. Biophys. Res. Commun. 2014, 450, $1021-1026$. [CrossRef]

236. Hall, Z.; Bond, N.J.; Ashmore, T.; Sanders, F.; Ament, Z.; Wang, X.; Murray, A.J.; Bellafante, E.; Virtue, S.; Vidal-Puig, A.; et al. Lipid zonation and phospholipid remodeling in nonalcoholic fatty liver disease. Hepatology 2017, 65, 1165-1180. [CrossRef] [PubMed]

237. Brunt, E.M.; Tiniakos, D.G. Histopathology of nonalcoholic fatty liver disease. World J. Gastroenterol. 2010, 16, 5286-5296. [CrossRef]

238. Gasmi, B.; Kleiner, D.E. Liver Histology Diagnostic and Prognostic Features. Clin. Liver Dis. 2020, 24, 61. [CrossRef]

239. Kleiner, D.E. Histopathological challenges in suspected drug-induced liver injury. Liver Int. 2018, 38, 198-209. [CrossRef] [PubMed]

240. Mori, S.; Arima, N.; Ito, M.; Fujiyama, S.; Kamo, Y.; Ueki, Y. Non-alcoholic steatohepatitis-like pattern in liver biopsy of rheumatoid arthritis patients with persistent transaminitis during low-dose methotrexate treatment. PLoS ONE 2018, 13, e0203084. [CrossRef] 